IZA DP No. 8704

Strategic Incomplete Contracts:

Theory and Experiments

Nisvan Erkal

Steven Y. Wu

Brian Roe

December 2014 


\title{
Strategic Incomplete Contracts: Theory and Experiments
}

\author{
Nisvan Erkal \\ University of Melbourne \\ Steven Y. Wu \\ Purdue University \\ and IZA \\ Brian Roe \\ Ohio State University
}

\section{Discussion Paper No. 8704 \\ December 2014}

\author{
IZA \\ P.O. Box 7240 \\ 53072 Bonn \\ Germany \\ Phone: +49-228-3894-0 \\ Fax: +49-228-3894-180 \\ E-mail: iza@iza.org
}

Any opinions expressed here are those of the author(s) and not those of IZA. Research published in this series may include views on policy, but the institute itself takes no institutional policy positions. The IZA research network is committed to the IZA Guiding Principles of Research Integrity.

The Institute for the Study of Labor (IZA) in Bonn is a local and virtual international research center and a place of communication between science, politics and business. IZA is an independent nonprofit organization supported by Deutsche Post Foundation. The center is associated with the University of Bonn and offers a stimulating research environment through its international network, workshops and conferences, data service, project support, research visits and doctoral program. IZA engages in (i) original and internationally competitive research in all fields of labor economics, (ii) development of policy concepts, and (iii) dissemination of research results and concepts to the interested public.

IZA Discussion Papers often represent preliminary work and are circulated to encourage discussion. Citation of such a paper should account for its provisional character. A revised version may be available directly from the author. 


\begin{abstract}

\section{Strategic Incomplete Contracts: Theory and Experiments}

We develop a model of strategic contractual incompleteness that identifies conditions under which principals might omit even costlessly verifiable terms. We then use experiments to test comparative statics predictions of the model. While it is well known that verifiability imperfections can limit complete contracting, researchers know less about how the degree of imperfection affects endogenous incompleteness, particularly with repeat trading. In our baseline treatment with perfect verifiability, subjects overwhelmingly used complete contracts to conduct trades, achieving nearly first best outcomes. In our partial verifiability treatment with a reduced set of verifiable performance levels, the results reversed and parties relied heavily on incomplete contracts that omitted even costlessly verifiable terms. However, the efficacy of incomplete contracts in outperforming available complete contracts depends critically on the continuation probability of repeat trading. With a small continuation probability, incomplete contracts did no better than complete contracts while exposing parties to considerable strategic uncertainty.
\end{abstract}

JEL Classification: C C73, C91, D86, J41, L14, L24, M52

Keywords: incomplete contract, relational contract, endogenous incompleteness, informal incentives, experimental economics

Corresponding author:

Steven Y. Wu

Purdue University

Department of Agricultural Economics

403 West State Street

West Lafayette

IN 47907-2056

USA

E-mail: sywu@purdue.edu

\footnotetext{
*We thank Tom Wilkening, Tim Cason, Vai-Lam Mui, Klaus Abbink and seminar participants at Purdue University, Monash University, University of Sydney, and the North American Economic Science Association Conference in Santa Cruz for helpful comments. Any remaining errors are ours. Sharon Raszap and Amy Beth Corman provided excellent research assistance. The authors gratefully acknowledge financial support provided by the USDA-NIFA grant award no. 2010-65400-20430, and Tim Cason for providing access to the Vernon Smith Experimental Laboratory at Purdue University. This research is not the result of a for-pay consulting relationship.
} 


\section{Introduction}

In this study, we investigate the question of why contracts used in practice often appear to be strategically incomplete in that they omit important terms that can be verified by a third-party at relatively low cost. For instance, Scott (2003) collected information on a large number of contracts and found that a surprising number did not condition performance on verifiable performance measures that can be specified in a contract at low cost. It is well known that contractual incompleteness can lead to hold-up problems and post contractual opportunism; hence, legal scholars and economists have been puzzled as to why real world contracts often appear to be deliberately incomplete even when there are no explicit costs to including some verifiable terms.

To address the above question, we develop a relational contracting model of optimal strategic incompleteness with testable implications and then empirically investigate these implications using economic experiments. While we are not the first to theoretically investigate incompleteness within a relational contracting framework, our major contributions are that (1) we identify conditions under which contract drafters may strategically omit even costlessly verifiable contractual terms and (2) we investigate empirically how people actually endogenously structure incomplete contracts. Indeed, many of our experimental subjects chose to omit easily verifiable contract terms in treatments that are theoretically favorable for incomplete contracts. Our model also allows us to identify conditions in which the use of complete contracts dominate incomplete contracts both in terms of joint surplus and a reduction in strategic uncertainty. We find that in treatments where complete contracts provide such favorable conditions, subjects overwhelmingly chose to use complete contracts.

As a starting point for our analysis, we develop a principal-agent model that 
allows contractual form to emerge endogenously from an optimization problem. We show that endogenous incompleteness can emerge even in the absence of explicit contracting costs, bounded rationality and costs of cognition. ${ }^{1}$ That is, endogenous incompleteness can be strategic. The key ingredient is that there has to be some imperfection in the performance measurement technology that allows a third-party to verify performance.

While it is well known that some imperfection in performance measurement is needed for endogenous incompleteness, we identify precisely the degree of imperfection required. To do this, we model the degree of imperfection as a spectrum ranging from an empty contractible set of performance levels, which is the usual assumption in the relational contracting literature, to a very rich and dense set that includes contractible performance levels that are arbitrarily close to the first best level. Only when imperfection leads to the absence of contractible performance levels that are "sufficiently close" (to be made precise in the theoretical section) to first best do we get strategically incomplete contracts. Intuitively, when contractible performance levels deviate too far from first best, then the contracting parties prefer not to use the verifiable performance levels in a contract and instead prefer incomplete contracts that possibly allow them to achieve non-contractible performance levels that are closer to first best. A caveat, however, is that the parties must be able to self-enforce noncontractible performance levels, so self-enforcement (such as via repeat trading) is another important ingredient for endogenous incompleteness.

Our model also generates comparative static insights about how exogenous changes in the quality of the third-party enforcement technology and the discount factor (to vary the strength of self-enforcement) affects optimal contract structure. These com-

\footnotetext{
${ }^{1}$ This is not to say that these factors do not contribute contractual incompleteness; our goal is simply to isolate the importance of enforcement environment in driving endogenous incompleteness. Extensions of our study might examine the incremental impact of adding these additional factors.
} 
parative statics predictions form the basis for our experimental design. Our experimental design places very few restrictions on the contractual choice set available to subjects. The experiment is framed as a buyer (principal)-seller (agent) relationship where the buyer contracts with a seller to purchase a unit of a good that can vary in quality (performance variable). Our design can nest popular contracts seen in the literature such as fixed price contracts, which encompass efficiency wage, gift-exchange, or repeat purchase mechanisms (e.g. Shapiro and Stiglitz (1984); Akerlof (1982); Klein and Leffler (1981)); discretionary bonus contracts (e.g. Levin (2003); MacLeod and Malcomson (1989)); and "illusory promises" (e.g. Boot et al. (1993)). Infinitely repeated trading in the experiments is implemented using a fairly standard random continuation rule.

Our main treatment variation has to do with the efficacy of third-party enforcement of quality. In the perfect enforcement treatment (E), a third-party (the computer) can perfectly enforce quality and price. Thus, it is possible to achieve perfect enforcement of contracts. In the partial enforcement treatments (PE), third-party enforcement of quality is imperfect. This mimics an environment where, for example, a third-party can determine discrete differences in quality such as whether a product is defective or not, but cannot detect fine gradations in quality. One can think of this as a technology that allows parties to contract on "not defective" but not on more refined quality levels that are closer to first best. In both treatments, subjects are allowed to endogenously choose whether they want to avail themselves of third-party enforcement or whether to leave everything informal. In addition, for the partial enforcement treatment, we examine two sub-treatments by varying the probability of continuation between 0.5 (expected two period repeated game) and 0.8 (expected five period repeated game). This sub-treatment allows us to examine the interaction between formal enforcement and self-enforcement since an increase in continuation 
probability increases the strength of self-enforcement.

Our main findings are as follows. First, with no imperfections in the third-party enforcement technology, subjects overwhelmingly used complete contracts to conduct transactions ( $81 \%$ of trades). Moreover, nearly half the trades resulted in first best levels of quality despite the fact that we designed the experiment so that first-best quality is an interior solution and ensured that it is not an obvious focal point. This suggests that with sufficiently strong third-party enforcement of contracts, trading outcomes can be highly efficient. This result is consistent with canonical contract theory that emphasizes the importance of complete contracts.

Second, with imperfections in third-party enforcement and a high continuation probability of 0.8 , the results reversed. Approximately $65 \%$ of such trades involved the use of endogenously incomplete contracts that omit even costlessly variable quality levels in the contractible set. However, when self-enforcement weakened, as captured by a treatment with a continuation probability of only 0.50 , the majority of trades were still conducted using complete contracts. Thus, there is a strong interaction between the third-party enforcement technology and reputation effects in driving strategic incompleteness. These results are among the first that we are aware of that provide empirical insight into "second generation" incomplete contracting models discussed by Aghion and Holden (2011). ${ }^{2}$

We also empirically analyzed several important determinants of strategic incompleteness. For instance, the choice of contract was primarily driven by the motivation to provide incentives on the intensive margin (ensure higher quality) rather than the extensive margin (ensure seller participation). Moreover, we found significant counter-party risk associated with promised discretionary bonuses that did not sat-

\footnotetext{
${ }^{2}$ In their survey paper, Aghion and Holden (2011) refer to second generation models as those that examine how endogenous incompleteness responds to various determinants, including discount rates and reliance on relational contracts (p.194).
} 
isfy self-enforcement constraints in incomplete contracts. Bonuses that were too large were not credible. Sellers tended to reject contracts with promised bonuses that were "too good to be true" and their foresight was correct on average, as principals tended to shirk on paying non-credible bonuses. On the other hand, when promised bonuses were too low to satisfy agent's self-enforcement constraints, agents shirked on quality.

\section{Related Literature}

While the classical literature on incomplete contracts has focused on bounded rationality/unforeseen contingencies (e.g. Hart (1995)), explicit contracting costs (e.g. Battigalli and Maggi (2002, 2008); Kvaløy and Olsen (2009)), and enforcement costs (See Tirole (1999) for an overview), recent theoretical work has also focused on how repeat trading can alleviate inefficiencies that arise in one-shot environments (MacLeod (2007); Kvaløy and Olsen (2009)). In their recent survey article on incomplete contracts, Aghion and Holden (2011) point out that "second generation" models of incomplete contracts tend to focus on relational contracting and the determinants of endogenous contractual incompleteness. MacLeod (2007) suggests that the way people actually engage in repeat trading is not well understood and may potentially involve more complex contractual mechanisms than the classic efficiency wage form (Shapiro and Stiglitz (1984)) or repeat purchase mechanisms (Klein and Leffler (1981)). While some theoretical progress has been made toward understanding these issues, there is a shortage of empirical studies to complement theoretical developments. Along these lines, our paper makes a contribution to the literature on second generation models of incomplete contracts and adds some empirical evidence to the discussion of how people structure contracts in repeat trading environments.

Much of our work is motivated by the theoretical studies by Bernheim and Whin- 
ston (1998), Baker et al. (1994), and Boot et al. (1993). The theory of strategic ambiguity described by Bernheim and Whinston (1998) suggests that, when there are imperfections in third-party enforcement of contracts, greater incompleteness may enhance surplus by providing greater discretionary latitude to use informal incentives. Our study can be seen as an experimental test of strategic ambiguity which is arguably one of the most important theories of incomplete contracting. Similarly, Baker et al. (1994) suggest that if a principal has access to both objective and subjective performance measures, imperfections in the objective measure can cause trading parties to rely on informal contracts that rely on the subjective measure. While our model does not include two performance measures, our model does show that imperfections over a single performance measure can lead to similar results. Boot et al. (1993) emphasize the point that, while incomplete contracts that leave parties with more ex post discretion can increase performance in some situations, discretion also increases the scope for abuse. However, concern for future reputation may discipline the abuse of discretion so there is interplay between incompleteness and reputation. Our study shows that the use of incomplete contracts, which leaves more ex post discretion, increases with the discount factor. This suggests that, when the future is more important, incomplete contracts are more likely to emerge. One contribution of our research is that we capture the remarkable insights of Bernheim and Whinston (1998), Boot et al. (1993) and Baker et al. (1994) within a single principal-agent framework that is sufficiently parsimonious to facilitate experimental implementation and empirical testing. ${ }^{3}$ Our model precisely identifies important thresholds and interactions between third-party and self-enforcement that drive strategic incompleness. Finally, our model yields clean comparative statics predictions concerning how vari-

\footnotetext{
${ }^{3}$ Baker et al. (1994) also use a fairly parsimonious principal-agent framework though implementing two performance measures in the laboratory can be potentially too complicated for many experimental subjects.
} 
ations in the caliber of the third-party enforcement technology and the strength of self-enforcement induce strategic incompleteness.

Our paper is also related to the work of Kvaløy and Olsen (2009)(KO) who examine endogenous incompleteness within a relational contracting framework. However, our paper differs from KO's paper in that we consider contracting parties' motivation to omit even costlessly verifiable terms in a contract whereas $\mathrm{KO}$ examine the case where a principal can make costly ex ante preparations to improve the probability of third-party verification. Thus, the two papers examine different determinants of endogenous incompleteness in a complementary way with our specific focus being why contracting parties seemingly omit even terms that are costless to verify.

There is also an experimental economics literature on incomplete contracts, the most notable being the novel work of Ernst Fehr and colleagues (e.g. Fehr et al. (1997); Fehr and Falk (1999); Fehr and Gächter (2000); Brown et al. (2004); Fehr et al. (2007) among others). However, our objectives are fundamentally different from the objectives of these papers as we use standard methodology to study a long-standing question in the contract theory literature concerning why contracts are incomplete in the first place, whereas these papers examine how recent behavioral theories can alleviate inefficiencies arising from contractual incompleteness. Nonetheless, we view our paper as complementary to these papers in providing insights into the nature of trading under incomplete contracts. Our paper also has some overlap with the work of Sloof and Sonnemans (2011)(SS) who study the interaction between explicit and relational incentives. While we focus on enforcement conditions that make contracts endogenously complete or incomplete in the first place, they focus on how sub-optimal explicit incentives can support relational contracts or trigger social preferences. Both papers find that weaker explicit contracts can support stronger relational contracts. The consistency in results holds despite substantial design differences between the SS 
experiments and ours, which suggests that the finding that weaker explicit incentives support informal incentives might be fairly robust. ${ }^{4}$

\section{Theoretical Framework}

\subsection{Model setup}

We assume that a principal contracts with an agent to produce one unit of a good for which quality is important. The typical assumption in the relational contracting literature is that the key performance variable (i.e. quality in our case) is mutually observable to the contracting parties but not to outsiders (Bernheim and Whinston, 1998; Levin, 2003; Dixit, 2007; MacLeod, 2007). This precludes the use of formal contracts that are third-party enforced. However, we relax this assumption by introducing a third-party enforcement technology that varies in precision and is exogenous to the principal and agent. By varying the caliber of the third-party enforcement technology, we can nest both formal contracting and relational contracting. To keep the analysis from getting overly complex, we abstract away from asymmetric information problems. Thus, our environment is similar to MacLeod and Malcomson (1989) where the key barrier to contracting is related to enforcement problems.

Before describing the enforcement technology in detail, we first emphasize an assumption that is important for defining the contractible set for a given enforcement technology. Note that under a contractual agreement, each party has obligations to take actions consistent with the agreement. We can specify the principal and agent's

\footnotetext{
${ }^{4}$ For example, Sloof and Sonnemans use a reduced form contracting environment where they impose a restricted set of contracts (trust games) on subjects. Our experimental design is based on a fully specified principal-agent model that imposes very few restrictions on contractual form; i.e. contract structure emerges endogenously subject to incentive compatibility constraints, participation constraints, and enforcement limits. In addition, in their design, it is the agent who makes the contract choice whereas in our model, the principal designs the contract.
} 
actions generically as $a_{i} \in A_{i}$ where $i=A, P$.

Assumption 1. There is an agency confict in that for $a_{A}{ }^{\prime}>a_{A}{ }^{\prime \prime}$ and $a_{P}{ }^{\prime}>a_{P}{ }^{\prime \prime}$, where $a_{A}{ }^{\prime}, a_{A}{ }^{\prime \prime} \in A_{A}$ and $a_{P}{ }^{\prime}, a_{P}{ }^{\prime \prime} \in A_{P}$, we have: $\pi_{P}\left(a_{P}, a_{A}{ }^{\prime}\right)>\pi_{P}\left(a_{P}, a_{A}{ }^{\prime \prime}\right)$; $\pi_{P}\left(a_{P}{ }^{\prime}, a_{A}\right)<\pi_{P}\left(a_{P}{ }^{\prime \prime}, a_{A}\right) ; \pi_{A}\left(a_{P}, a_{A}{ }^{\prime}\right)<\pi_{A}\left(a_{P}, a_{A}{ }^{\prime \prime}\right) ;$ and $\pi_{A}\left(a_{P}{ }^{\prime}, a_{A}\right)>\pi_{A}\left(a_{P}{ }^{\prime \prime}, a_{A}\right)$

In words, ceteris paribus, the principal's payoff is increasing in the agent's action and decreasing in her own actions. The opposite is true for the agent. This assumption easily holds in our model where the agent's action/obligation is to deliver quality level $q \geq Q$ where capital $Q$ refers to the quality level specified in the contract and $q$ refers to the actual quality delivered. The principal's action/obligation is to make a total payment $w=p+b \geq W$ where $w$ is total actual payment and $W$ is the total obligated payment under the contract. The total payment $w$ can consist of a salary or base price $p$ and a bonus payment $b$. We use capitalized $P$ and $B$ to denote the contractually specified promised payments. The parties' payoff functions are assumed to be $\pi_{P}=r(q)-p-b$ and $\pi_{A}=p+b-c(q)$ where $r(q)$ and $c(q)$ are differentiable functions such that $r^{\prime}(q)>0, r^{\prime \prime}(q) \leq 0, c^{\prime}(q)>0$ and $c^{\prime \prime}(q) \geq 0, \forall q \in[\underline{q}, \check{q}] \subset \mathbb{R}_{+}$. Here, the principal prefers higher quality all else equal and the agent always prefers higher payment, all else equal. The reservation payoffs for the principal and agent are $\bar{\pi}$ and $\bar{u}$, respectively. We make the additional assumption that there exists some minimal quality threshold $\bar{q} \in(\underline{q}, \breve{q})$ such that $r\left(q^{h}\right)-c\left(q^{h}\right) \geq \bar{u}+\bar{\pi}>r\left(q^{l}\right)-c\left(q^{l}\right)$ for $q^{l} \in[\underline{q}, \bar{q})$ and $q^{h} \in[\bar{q}, \breve{q}]$. This implies that some minimum quality level must be produced to generate positive surplus.

Our enforcement technology is based on the verifiability constraints of Bernheim and Whinston (1998) although our specification extends their framework to accommodate continous action spaces and to define a contractible set of actions.

Definition 1. The enforcement technology is an ordered partition of $A_{i} \subset \mathbb{R}$, 
$E_{i}=\left\{e_{i 1}, \ldots, e_{i N_{i}}\right\}$ where each subset of the partition is left closed, the mesh of the partition decreases with $N_{i}$, all actions are ordered from lowest to highest both within and across subsets, and a third-party cannot distinguish any two actions that belong to the same subset $e_{\text {in }}$ but can distinguish two actions that belong to different subsets of the partition, $e_{i k}$ and $e_{i l}$, where $k \neq l$.

The assumption that the mesh of the partition is decreasing in $N_{i}$ is required to guarantee that the enforcement technology improves as the number of subintervals in the partition increases. For example, if the mesh did not decrease as $N_{i}$ tends to infinity and the first best action is in the mesh, then increasing the number of subintervals would not impact the ability to contract for first best.

Assumption 1 implies, ceteris paribus, party $i$ tries to minimize her actions in $A_{i}$ but party $j$ prefers higher actions in $A_{i}$; i.e., the principal's payoff is monotonically increasing in $a_{A} \in A_{A}$ while the agent's payoff is monotonically decreasing in $a_{A} \in A_{A}$. Similarly, the principal's payoff is monotonically decreasing in $a_{P} \in A_{P}$ while the agent's payoff is monotonically increasing in $a_{P} \in A_{P}$. This implies that each party will seek to minimize his own actions while desiring that the counter-party chooses higher actions. Thus, a contract is needed to coordinate desirable actions. However, only certain actions are contractible; i.e. third-party enforceable. Since each party wants to minimize his own actions, only the smallest action in each subset of the partition is contractible. This allows us to define the contractible set.

Definition 2. The contractible set for $i=A, P$ is defined as $\underline{E_{i}}=\left\{\underline{e_{i 1}}, \underline{e_{i 2}}, \ldots, \underline{e_{i N_{i}}}\right\}$ where $\underline{e}_{i n}$ is the infimum of $e_{i n} \forall n=1,2, \ldots, N_{i}$.

In other words, only the smallest action in each subset of the partition can be third-party enforced. Improvements in the enforcement technology can be modeled via finer partitions of $E_{i}$ so that an increase in $N_{i}$ implies an increase in the number 
of contractible actions in the contractible set.

To illustrate both the enforcement technology and contractible set, consider a simple example where $q \in A_{A}=[0,10]$ and the enforcement technology is $E_{A}=$ $\left\{e_{A 1}, e_{A 2}, e_{A 3}\right\}=\{[0,3),[3,7),[7,10)\}$, which has an associated contractible set of $\underline{E_{A}}=\{0,3,7\}$. An example of a refinement of this enforcement technology would be $E_{A}^{\prime}=\left\{e_{A 1}, e_{A 2}, e_{A 3}, e_{A 4}, e_{A 5}, e_{A 6}\right\}=\{[0,2),[2,4),[4,6),[6,8),[8,10),\{10\}\}$ with the contractible set $E_{A}^{\prime}=\{0,2,4,6,8,10\}$. Here, $E_{A}^{\prime}$ is the superior enforcement technology as it allows the parties to formally contract over a greater range of $Q$. Thus, finer partitions are synonymous with better enforcement technologies.

While the contractible set of actions is countable, as the enforcement technology improves, the contractible set $\underline{E_{A}}$ will approximate $A_{A}$. We say approximate rather than converge because $\underline{E_{A}}$ can only be made countably infinite whereas $A_{A}$ is a subset of real numbers. Therefore $A_{A}$ will always have greater cardinality. Nonetheless, $\underline{E_{A}}$ is dense in $A_{A}$ since every point in $A_{A}$ is either in $\underline{E_{A}}$ or can be made arbitrarily close to a member of $\underline{E_{A}}$ if the partition is made fine enough.

Lemma 1. Consider a principal-agent relationship that is constrained by the enforcement technology and contractible set specified in Definitions 1 and 2. Let $q^{*} \in A_{A}$ denote the first-best level of quality; i.e. $q^{*}=\operatorname{argmax}\{r(q)-c(q)-\bar{\pi}-\bar{u}\}$. Then for every $\epsilon>0$, there exists a partition of $A_{A}$ with $N_{A}>N_{\epsilon}$ that has an associated contractible set $\underline{E_{A_{\epsilon}}}$ that contains a contractible quality level $\underline{q_{f_{\epsilon}}}$ such that $\left|\underline{q_{f_{\epsilon}}}-q^{*}\right|<\epsilon$.

Proof: See Appendix A for all proofs.

In other words, in the limit, as the partition gets fine enough, it is possible to contract for first best quality level. Thus, the enforcement apparatus developed in this section can nest both the complete absence of third-party enforcement (when $N_{A}=1$ ) and perfect third-party enforcement (when $N_{A} \rightarrow \infty$ ). 


\subsection{Conceptualizing Contractual Incompleteness}

Under a complete contract, a complete state-contingent plan governs performance. Therefore, all performance obligations of both parties are fully specified for all contingencies in the initial contract. Moreover, the contract is third-party enforced by a court and sufficient penalties exist to deter both parties from shirking on their obligations. This implies that no party has ex post discretionary latitude to deviate from the initial contract. One can view the presence of ex post discretionary latitude to deviate as being synonymous with an incomplete contract.

Our enforcement technology machinery gives us a precise way of specifying both complete and incomplete contracts. To illustrate, recall our earlier example where $A_{A}=[0,10]$ and $E_{A}=\left\{e_{A 1}, e_{A 2}, e_{A 3}\right\}=\{[0,3),[3,7),[7,10)\}$, which has an associated contractible set of $\underline{E_{A}}=\{0,3,7\}$. Here, despite the enforcement technology being imperfect, it is still possible to write a complete contract. The complete contract can either specify state-contingent prices $P_{0}, P_{3}$, and $P_{7}$ to be paid under each contractible quality realization, or the principal can specify, for example, $Q=7$ in exchange for a fixed payment $P_{7}$ (we will refer to this as the "simple contract"). In the former case, a third-party enforces the contingent payments $P_{0}, P_{3}$, and $P_{7}$ whereas in the simple contract, a third-party enforces $Q=7$ and $P_{7}$ directly. Note that in either case, all variables are third-party enforceable since they are either in the contractible set or depend only on variables in the contractible set. If the contingent payments $P_{0}, P_{3}$, and $P_{7}$ are chosen in an incentive compatible manner to implement $q=7$, then the two types of contracts are outcome equivalent in that they both implement $q=7$. However, given the simplicity of the simple contract, we will focus on simple contracts going forward. The important point is that a simple contract is a complete contract because it can credibly tie down all obligations so that neither party has ex 
post discretion to deviate. Hence, imperfections in the enforcement technology does not preclude the possibility of writing complete contracts, though imperfections do limit the set of available complete contracts.

What does an incomplete contract look like? There is no unique incomplete contract, but we will provide one example for illustration purposes. Suppose a contract specifies $Q=10$, a fixed payment $P_{10}$ and a bonus $B$ if $q=10$ is realized. Because $Q=10$ is not in the contractible set, it follows that the agent has ex post discretion to deviate from $Q=10$ without legal consequence. Additionally, because $B$ is contingent on $q=10, B$ is a discretionary bonus that is not contractible. Therefore, the principal can shirk on the bonus even if the agent performs. The important point is that both parties have ex post discretion to deviate from the initial agreement.

The traditional incomplete contracts literature has recognized the damaging effects of ex post discretionary latitude through various examples, case studies and formal models. The crux of the issue can be illustrated with the above incomplete contract. Note that the principal would offer a contract that just satisfies the agent's participation and incentive compatibility constraints. The participation constraint is $\pi_{A}=P_{10}+B-c(10)=\bar{u}$, where $\bar{u}$ is the agent's reservation utility. The incentive compatibility condition is $B=c(10)-c(0) . B$ can be substituted into the participation constraint to get $P_{10}=\bar{u}+c(0)$. Since this is a sequential game where the principal is the last mover, a rational principal would not pay an unenforceable bonus. Therefore, the agent would only receive $P_{10}-c(10)=\bar{u}+c(0)-c(10)<\bar{u}$ by delivering $q=10$. A rational, forward looking agent would then only choose $q=0$ to ensure a payoff of $\bar{u}$. Backward inducting one more stage, the principal expects to earn only $\pi_{P}=r(0)-P_{10}=r(0)-\bar{u}-c(0)<\bar{\pi}$ and offers no contract. Even if there is no clear last mover or certain factors are only contractible ex post, the parties may still have to engage in bargaining which might also create inefficiencies. 
We now introduce more notation that will be used frequently for the remainder of the paper. We denote $\pi_{f}^{N_{A}}$ and $u_{f}^{N_{A}}$ to be the payoffs obtained from the "best" complete contract for an enforcement technology of partition size $N_{A}$. The "best" complete contract is the one that yields the highest joint surplus under the enforcement technology. We denote $Q_{f}^{N_{A}}$ as the associated best contracted level of quality, and $q_{f}^{N_{A}}$ to be the best actual quality delivered, but under a complete contract, $Q_{f}^{N_{A}}=q_{f}^{N_{A}}$. To illustrate, suppose surplus, $S(q)=r(q)-c(q)-\bar{\pi}-\bar{u}$, is monotonically increasing in quality over $A_{A}=[0,10] .^{5}$ Then for the contractible set $\underline{E_{A}}=\{0,3,7\}$, the complete contract that specifies $Q=7$ in exchange for a fixed payment $P_{7}$ is the complete contract that yields the highest surplus. No other complete contract dominates it since a complete contract for $Q>7$ is not feasible and a complete contract for $Q<7$ does not yield as high of surplus. Therefore, for $N_{A}=3, Q_{f}^{3}=q_{f}^{3}=7$.

More generally, the efficiency of complete contracts improves with the enforcement technology. For fine enough partitions, a complete contract can implement quality levels that are close to first best.

Lemma 2. Let $S_{f}^{N_{A}}=\pi_{f}^{N_{A}}+u_{f}^{N_{A}}-\bar{u}-\bar{\pi}=r\left(q_{f}^{N_{A}}\right)-c\left(q_{f}^{N_{A}}\right)-\bar{u}-\bar{\pi}$ denote the surplus generated by the best complete contract. Then $\lim _{N_{A} \rightarrow \infty} S_{f}^{N_{A}}=S\left(q^{*}\right)$.

\subsection{Optimal Contracting}

In this section, we will show how the optimal contract structure can be made endogenous to the enforcement technology. Our foundational model is a principal-agent model of relational contracting with symmetric information. The enforcement technology acts as an exogenous constraint to the contract design problem. We can

\footnotetext{
${ }^{5}$ The assumption of monotonicity is made only to keep this example simple. Monotonicity need not be true in general. For example, for a continuous quality space, there could be an optimal level of quality. Going beyond that level may reduce joint surplus as marginal returns may be less than the marginal costs.
} 
exogenously vary the quality of the enforcement technology to generate comparative statics predictions about the types of optimal contracts used by the principal. Thus, the incomplete contractual form can be endogenized. Repeat trading facilitates the use of incomplete contracts because, as noted by Boot et al. (1993), reputation concerns can discipline the abuse of ex post discretion that exists under an incomplete contract.

Let the agent's action set (quality choice) be denoted by $A_{A}=[\underline{q}, \check{q}] \subset \mathbb{R}_{+}$where the enforcement technology, $E_{A}$, (see Definition 1) is a partition of $A_{A}$. To economize on notation, we do not specify the principal's action set because the agent's quality choice is the only determinant of efficiency and the principal's actions are only contingent on agent's quality (i.e. the discretionary bonus). We also define a binary variable $\alpha \in\{0,1\}$ where $\alpha$ equals 1 if $u_{f}^{N_{A}}+\pi_{f}^{N_{A}} \geq \bar{u}+\bar{\pi}$ and 0 otherwise. That is, $\alpha=1$ if the best complete contract delivers joint profits that exceed joint profits from the parties' reservation payoffs. The timeline within a stage-game follows the typical textbook principal-agent sequence:

1. The principal offers a contract, which is an agreement over a price/bonus/quality triplicate, $(P, B, Q)$.

2. The agent decides whether to accept or reject. If rejected, the principal and agent default to the best formal contract if $u_{f}^{N_{A}}+\pi_{f}^{N_{A}} \geq \bar{u}+\bar{\pi}$ (i.e. $\alpha=1$ ) and to their outside options, which yield payoffs $\bar{u}$ and $\bar{\pi}$, otherwise (i.e. $\alpha=0$ ).

3. If accepted, the agent chooses actual quality $q$.

4. The principal observes $q$ and chooses actual bonus $b$. The promised fixed payment, $P$, is also made. ${ }^{6}$

\footnotetext{
${ }^{6}$ Recall that the promised fixed payment is always third party enforceable because it is not contingent on quality. Therefore, the principal has no ex post discretion to deviate from $P$.
} 
A relational contract is an infinite repetition of the above contracting stage-game so that in each period $t$ and for each history up to $t$, the relational contract describes a sequence (1)-(4). Moreover, the relational contract is self-enforcing if it describes a subgame perfect equilibrium of the infinitely repeated game. In addition, Levin (2003) and Halac (2012) have shown that, with symmetric information, the optimal contract is stationary in that the same (optimal) contract is offered in every $t .^{7}$ Letting $\delta$ be the discount factor and multiplying the payoffs by $1-\delta$ to express them as per-period averages, the principal's contract design problem is:

$$
\begin{gathered}
\max _{Q, P, B}(1-\delta)[r(Q)-P-B]+\delta V[C] \quad s . t . \\
(1-\delta)[r(Q)-P-B]+\delta V[C] \geq \alpha \pi_{f}^{N_{A}}+(1-\alpha) \bar{\pi} \\
(1-\delta)[P+B-c(Q)]+\delta U[C] \geq \alpha u_{f}^{N_{A}}+(1-\alpha) \bar{u} \\
(1-\delta)[r(Q)-P-B]+\delta V[C] \geq(1-\delta)[r(Q)-P]+\delta\left[\alpha \pi_{f}^{N_{A}}+(1-\alpha) \bar{\pi}\right] \\
(1-\delta)[P+B-c(Q)]+\delta U[C] \geq(1-\delta)[P-c(\underline{q})]+\delta\left[\alpha u_{f}^{N_{A}}+(1-\alpha) \bar{u}\right]
\end{gathered}
$$

Constraints 2 and 3 are the participation constraints and 4 and 5 are the dynamic incentive compatibility or self-enforcement constraints. To understand the expressions $V(C)$ and $U(C)$, let $\Gamma$ denote the set of feasible contracts, which can be partitioned as $C \bigcup F=\Gamma$ and $C \cap F=\emptyset$. Then either $(P, B, Q) \in C$ or $F$, where the "C" contracts

\footnotetext{
${ }^{7}$ Nonstationary contracts arise primarily in the context of private information where one has to model relational dynamics due to the revelation of the private information over time (e.g. see Halac (2012) or Yang (2013)). It is important to point out that nearly all experiments involve some dynamics simply because subjects need to learn how to play the game. Hence, researchers typically treat predictions arising from stationary symmetric information games as theoretical benchmarks that subjects should converge to after sufficient rounds of learning. The actual dynamics that lead to the convergence is typically not of theoretical interest and early period departures from theoretical benchmarks is treated as noise that can be reduced if subjects are given adequate time to gain experience. Thus, to test the comparative statics predictions generated from our model, every effort was made to ensure that our experimental design provides subjects with sufficient rounds of play.
} 
are relational contracts that satisfy contraints 2-5, and "F" denotes "formal" (i.e. complete) contracts that satisfy participation constraints. Thus, $V(C)$ and $U(C)$ are the flow payoffs for the principal and agent, respectively, from the optimal selfenforcing relational contract $(P, B, Q) \in C$. If either party shirks on the relational contract or the principal offers a relational contract that fails to satisfy constraints $2-5$, then the parties respond by refusing to engage in relational contracting in the future; they will either rely on complete contracts or select their outside options. ${ }^{8}$ Due to stationarity, the same contract is offered every $t$, problem 1 becomes essentially a static optimization problem.

Proposition 1. The solution to optimization problem 1 yields an optimal stationary contract that requests some $\tilde{Q} \leq Q^{*}$ where $Q^{*}$ is a request for the first best quality level. The associated payment scheme is $W(\tilde{Q})=\tilde{P}+B(\tilde{Q})$ such that:

$$
\begin{aligned}
& \text { 1. } \frac{\alpha u_{f}^{N_{A}}+(1-\alpha) \bar{u}+c(\tilde{Q})}{1-\delta}-\frac{\delta}{1-\delta}\left\{r(\tilde{Q})-\alpha \pi_{f}^{N_{A}}-(1-\alpha) \bar{\pi}\right\} \leq \tilde{P} \leq \alpha u_{f}^{N_{A}}+(1-\alpha) \bar{u}+c(\underline{q}) \\
& \text { 2. } c(\tilde{Q})-c(\underline{q}) \leq B(\tilde{Q}) \leq \frac{\delta}{1-\delta}\left\{r(\tilde{Q})-c(\tilde{Q})-\alpha \pi_{f}^{N_{A}}-(1-\alpha) \bar{\pi}-\alpha u_{f}^{N_{A}}-(1-\alpha) \bar{u}\right\} \\
& \text { 3. } \tilde{P}+B(\tilde{Q})-c(\tilde{Q})=\alpha u_{f}^{N_{A}}+(1-\alpha) \bar{u}
\end{aligned}
$$

In words, under the optimal contract, the principal will contract for a quality level that is less than or equal to the first best quality level. Moreover, the discretionary bonus must simultaneously satisfy both the agent's and principal's self-enforcement constraints. Finally, the base price $P$ and the discretionary bonus must be simultaneously chosen to force the agent's participation constraint to bind with equality.

For a more intuitive look at self-enforcement, we can also solve condition (2) in

\footnotetext{
${ }^{8}$ Another possibility is that they might restructure the relational contract so that the breaching party receives only his/her reservation payoff. This possibility makes relational contracts renegotiation proof (Levin, 2003)
} 
Proposition 1 for $\delta$ which yields:

$$
\begin{aligned}
\delta \geq \underline{\delta}(Q) & =\frac{c(Q)-c(\underline{q})}{r(Q)-c(\underline{q})-\alpha\left[\pi_{f}^{N_{A}}+u_{f}^{N_{A}}\right]-(1-\alpha)[\bar{\pi}+\bar{u}]} \\
& =\frac{c(Q)-c(\underline{q})}{r(Q)-c(\underline{q})-\alpha\left[r\left(Q_{f}^{N_{A}}\right)-c\left(Q_{f}^{N_{A}}\right)\right]-(1-\alpha)[\bar{\pi}+\bar{u}]}
\end{aligned}
$$

The above critical value $\underline{\delta}(Q)$ is the threshold for the incomplete contract to be selfenforcing. Notice that the threshold depends on $Q$; therefore, if the principal wants to implement a higher $Q$, this puts pressure on self-enforcement. Consequently, the need for self-enforcement can limit the quality level that can be implemented. Finally, the threshold also depends on the payoffs $u_{f}^{N_{A}}$ and $\pi_{f}^{N_{A}}$, which in turn, depend on the efficacy of the enforcement technology. This suggests a non-trivial interaction between self-enforcement and third-party enforcement.

To see the interaction, suppose that $Q_{f}^{N_{A}}$ is the enforceable quality level that yields the highest joint surplus among all contractible quality levels. Thus, a complete con$\operatorname{tract}\left(Q_{f}^{N_{A}}, P_{f}^{N_{A}}\right)$ yields payoffs $\pi_{f}=P_{f}^{N_{A}}-c\left(Q_{f}^{N_{A}}\right)$ and $u_{f}^{N_{A}}=P_{f}^{N_{A}}-c\left(Q_{f}^{N_{A}}\right)$. These payoffs can be substituted in the middle term of 6 to get the last term of 6 . One can now conduct comparative statics analysis by letting $N_{A}$ in the enforcement technology increase, which would make $E_{A}$ a more refined partition of $A_{A}$. This in turn, increases the joint profit $r\left(Q_{f}^{N_{A}}\right)-c\left(Q_{f}^{N_{A}}\right)$ which weakly raises the threshold for selfenforcement $6 .{ }^{9}$ In short, an improvement in the enforcement technology should cause some relational contracts to unravel and be replaced by complete contracts. The following proposition provides specific conditions under which the parties endogenously use an incomplete contract over a complete contract.

\footnotetext{
${ }^{9}$ We say weakly because if $\alpha=0$, then the threshold does not change until joint surplus under the complete contracts exceeds joint surplus from the outside options, triggering $\alpha=1$.
} 
Proposition 2. Let $Q^{*}$ be the first best quality request such that $Q^{*} \in \underset{Q}{\arg \max }\{S(Q)\}$. If there exists $\tilde{Q}$ such that $S\left(Q^{*}\right) \geq S(\tilde{Q})>S\left(Q_{f}^{N_{A}}\right)$ and $\delta \geq \underline{\delta}(\tilde{Q})$, then an incomplete contract that implements $\tilde{Q}$ is preferred over the best complete contract.

Proposition 2 states that if there is enough imperfection in the enforcement technology, which allows for the existence of some self-enforcing level of $\tilde{Q}$ that yields joint surplus that is greater than what is obtainable under the best complete contract, then the parties will eschew a complete contract and instead relational contract for $\tilde{Q}$.

The above model can also be used to generate some comparative statics predictions that will be useful for organizing our experimental design and data analyses. Specifically, we focus on how exogenous changes in self-enforcement $(\Delta \delta)$ and thirdparty enforcement $\left(\Delta N_{A}\right)$ affects contracting outcomes.

Corollary 1. The following comparative statics follow from the above model:

1. (Exogenous change in enforcement technology): Consider the enforcement technology $\underline{E_{A}}=\left\{\underline{e_{A 1}}, \underline{e_{A 2}}, \ldots, \underline{e_{A N_{A}}}\right\}$ and let $\tilde{Q} \in \tilde{\mathbb{Q}}=\left\{\tilde{Q}: S\left(Q^{*}\right) \geq S(\tilde{Q})>\right.$ $\left.S\left(Q_{f}^{N_{A}}\right)\right\}$. As $N_{A} \rightarrow \infty$, then $\underline{\delta}(\tilde{Q}) \rightarrow 1$ for any $\tilde{Q} \in \tilde{\mathbb{Q}}$ and all incomplete contracts are endogenously replaced with complete contracts.

2. (Exogenous change in $\delta)$ : Suppose that $\tilde{Q}$ is such that $S(\tilde{Q})>S\left(Q_{f}^{N_{A}}\right)$ and $\delta \geq \underline{\delta}(\tilde{Q})$. Then an exogenous decrease in $\delta$ has the following effects:

(a) If $\delta \geq \underline{\delta}(\tilde{Q})$ continues to hold, then the principal continues to contract for $\tilde{Q}$ using an incomplete contract.

(b) If $\delta<\underline{\delta}(\tilde{Q})$, then the principal contracts for a lower $\hat{Q}$ where $\delta=\underline{\delta}(\hat{Q})$ using an incomplete contract if $S(\hat{Q})>S\left(Q_{f}^{N_{A}}\right)$.

(c) If $\delta<\underline{\delta}(\tilde{Q})$, then the principal switches to a complete contract that implements $Q_{f}^{N_{A}}$ if there exists no $\hat{Q}$ such that $S(\hat{Q})>S\left(Q_{f}^{N_{A}}\right)$ 
The key testable implications of the above corollary are that an improvement in the enforcement technology will increase the use of complete contracts over relational contracts. Moreover, a decrease in $\delta$ can lead to a decrease in the quality level that the principal contracts for and/or the decreased use of relational contracts.

\section{Experimental Design}

Our experimental design is based on the above contracting model though we did have to impose specific parameters and functional forms and these are described in detail below. However, the functional forms and parameters were chosen to fall within the general assumptions imposed in the theoretical model so that results can be interpreted with minimum loss of generality. In addition, our principal-agent relationship was framed as a buyer (principal) - seller (agent) relationship for the experiments.

Note that a crucial aspect of our design is that we must allow buyers to endogenously choose contractual form subject to exogenously imposed limits on the enforcement technology. To achieve this, we first specify sellers' action space as $q \in A_{A}=\{1,2, \ldots, 15\}$ where our sellers can only choose a natural number between 1 and 15 . While we can easily incorporate continuous values, we chose natural numbers to keep the action space simple for subjects. This allowed us to define two enforcement technologies which represents our major treatment variation:

1. Technology E: This is the perfect enforcement technology $E_{A}^{E}=\left\{e_{A 1}, e_{A 2}, \ldots, e_{A 15}\right\}=$ $\{\{1\},\{2\}, \ldots,\{15\}\}$. This technology allows a third-party to enforce every single quality level in $A_{A}$ so that the contractible set is $\underline{E}_{A}^{E}=A_{A}$. Here $N_{A}=15$.

2. Technology PE: This is the partial enforcement technology $E_{A}^{P E}=\left\{e_{A 1}, e_{A 2}\right\}=$ 
$\{\{1,2,3,4\},\{5,6, \ldots, 15\}\}$. The contractible set is $\underline{E}_{A}^{P E}=\{1,5\}$. Here $N_{A}=2$.

One can interpret Technology E as a technology that provides perfect grading of quality whereas Technology PE allows a third-party only to arbitrate on whether the product was defective or not (i.e. below or above 5). Thus, even under PE the parties can write a complete contract that conditions on whether the product is defective. To understand how we allow our buyers to endogenously structure complete contracts under both $\mathrm{E}$ and $\mathrm{PE}$, we now describe the contracting stage-game.

Within each stage-game, each buyer can (but is not required to) offer a contract, which is a triplicate $(P, B, Q)$ where $P \in\{0,1, \ldots, 200\}$ is a fixed price, $B \in$ $\{0,1, \ldots, 200\}$ is a discretionary bonus, and $Q \in\{1,2, \ldots, 15\}$ is the buyer's requested quality level. A crucial point to note is that we allowed buyers to specify "simple" complete contracts by specifying $Q \in \underline{E}_{A}$ along with a fixed price $P$ and then clicking a "binding" option on the computer screen. When binding is checked, neither party has ex post discretionary latitude to deviate as the computer enforces both $P$ and $Q$. A discretionary bonus $B$ is redundant since it plays no incentive role as the seller has no discretion to choose $q \neq Q .{ }^{10}$ Apart from these restrictions, we imposed no other structure on the contracts. Thus, our subjects can endogenously specify complete contracts as specified above, as well as a range of incomplete contracts seen in the literature including gift-exchange/efficiency wage contracts $(P>0, B=0)$, discretionary bonus contracts $(P>0, B>0)$, and "illusory promises" $(P=0, B>0)$. Specifying an incomplete contract only requires the buyer to check the "discretionary"

\footnotetext{
${ }^{10}$ We thank Tim Cason for pointing out that it is possible to create binding contracts that only prevent downward discretion which might allow subjects to express reciprocal behavior by delivering quality and/or bonuses beyond the contractually specified levels. We conducted some downward binding but upward discretionary sessions. Though there were some changes in numeric results, the qualitatively results and central conclusions did not change. Moreover, because our paper is not about social preferences and we did not integrate reciprocal behavior in our model, our theoretical predictions under the assumption of pure self-interest would not change. Hence, in order to maintain clarity and conserve space, we did not include the results of these additional sessions in this paper.
} 
box rather than the "binding" box. When discretionary is checked, $Q$ and $B$ are not enforced by the computer. $P$ is still guaranteed because a fixed payment can always be enforced since it is not contingent on anything that is imperfectly verifiable. ${ }^{11}$ The following summarizes the sequence of events in a stage-game.

1. Proposal phase-buyer can offer a single contract with terms $(P, B, Q)$ to seller.

- Contract can be made binding (quality 3rd party enforced) but in the PE treatments, the buyer can only make either $Q=1$ or $Q=5$ binding.

- The seller can accept or reject. So a participation constraint is active.

2. Quality phase-seller chooses $q$ if $Q$ is not binding.

3. Payment phase-if the buyer offered $B$, the buyer can choose actual $b$ to pay.

Note that under binding complete contracts, there are no Quality or Payment phases since neither party has ex post discretion to deviate from the initial contract.

While the stage-game is a one-shot contracting relationship, our theoretical model also allows for relational contracting, so our experimental design must permit repeat trading. We follow the typical approach of implementing an infinitely repeated game using a random continuation rule (e.g. Bó (2005)). Specifically, we exogenously formed buyer-seller pairs where the buyer and seller within each pairing can trade with each other for a random number of stage-games. In other words, in each period, there is $\delta$ probability that the same buyer and seller can trade with each other again the next period. This allows us to create a second treatment variation with respect to $\delta$ :

1. 0.8 treatment: $\delta=0.8-$ implies an expected five period repeated game. ${ }^{12}$

\footnotetext{
${ }^{11}$ In practice, even if no legal system existed, one can mimic the enforcement of $P$ simply by having the buyer pay it upfront.

${ }^{12}$ The expected number of periods is $\frac{1}{1-\delta}$.
} 
2. 0.5 treatment: $\delta=0.5$ - implies an expected two period repeated game.

Self-enforcement is obviously stronger in the 0.8 treatment because, in any given period, there is a larger probability that the two parties will trade in the following period. We refer to the repeated game for each buyer-seller pair as a supergame. Thus, in the 0.8 treatment, the expected length of a supergame is five periods and in the 0.5 treatment, the expected length of a supergame is two periods.

Table 1: Treatments

\begin{tabular}{lcc}
\hline & $\delta=0.5$ & $\delta=0.80$ \\
\hline Perfect enforcement (E) & & two sessions \\
\hline Partial enforcement (PE) & three sessions & three sessions \\
\hline
\end{tabular}

Our treatment variations are summarized in Table 1 . Note that we only ran the E treatment under $\delta=0.80$ because, by Corollary 1 part (1), when the enforcement technology is perfect, complete contracts should be used regardless of the size of $\delta$. Nonetheless, we ran the E treatment at $\delta=0.80$, which is the favorable $\delta$ level for incomplete contracting. If subjects use complete contracts under E0.80, then we can be confident that they will use complete contracts under E0.50.

With respect to parameterization, the stage-game payoffs are $\pi=12 q-p-b$ and $u=p+b-\left(q^{2}\right) / 2$ for the buyer and seller, respectively. Our sellers were provided with Table 2 so that they could quickly get their costs for each quality level. Reservation

Table 2: Seller's Cost

\begin{tabular}{|c|c|c|c|c|c|c|c|c|c|c|c|c|c|c|c|}
\hline Quality & 1 & 2 & 3 & 4 & 5 & 6 & 7 & 8 & 9 & 10 & 11 & 12 & 13 & 14 & 15 \\
\hline Cost & 1 & 2 & 5 & 8 & 13 & 18 & 25 & 32 & 41 & 50 & 61 & 72 & 85 & 98 & 113 \\
\hline
\end{tabular}

payoffs are $\bar{\pi}=\bar{u}=15$. These reservation payoffs are triggered if either the buyer does not offer a contract or the seller rejects a contract. First best is realized at $q=12$ which yields joint payoffs of 72 , which exceeds the joint payoffs of 30 if the 
parties do not contract. Also note that joint profit is below the joint outside option payoffs of 30 if $q<3$. Thus, it is risky for the parties to engage in contracting if the seller does not deliver at least $q>2$. Additionally, in the PE treatments, the best contractible quality is $Q_{f}^{2}=5$ which yields joint payoffs of 47.5 which exceed joint outside option payoffs. In the E treatment, even first best is in the contractible set, so $Q_{f}^{15}=12=Q^{*}$.

All interactions between subjects occurred via computers and subjects identified each other through assigned ID numbers that were not associated with actual identities. Once subjects were seated at their computer terminals, our z-Tree program randomly assigned half the subjects to be "buyers" (principals) and the other half to be "sellers" (agents). These roles were fixed for the duration of the experiment. The z-Tree program also randomly assigned ID numbers to each subject. Subjects were then read instructions and answered some control questionnaires to ensure understanding. After this, they conducted two trial periods to get accustomed to the computerized trading platform. Their ID numbers were suppressed during the trial periods. Once the live rounds began, each buyer was exogenously matched to a seller to play a supergame which consisted of a sequence of repeated stage-games until randomly terminated. The continuation probability following each stage game was either $\delta=0.8$ or $\delta=0.5$ depending on the treatment described above. No subjects were matched for more than one supergame, so we imposed stranger matching.

The experiment ended when one of two conditions occurred: (1) All possible supergame matches have been exhausted and the last pairing randomly terminates; (2) If all pairings have not been exhausted and the subjects have played at least 18 periods (across all supergames) in the $\delta=0.8$ treatment or at least 20 periods in the $\delta=0.50$ treatment, then they were in their last supergame and the experiment ended when that supergame terminated. These long period sessions were used to ensure 
there was adequate opportunity for learning to take effect. We recruited either 20 or 22 subjects per-session for our 0.5 experiments and either 16 or 18 subjects per-session for the 0.8 experiments. ${ }^{13}$

Our experiments were conducted in the Vernon Smith Experimental Economics Laboratory (VSEEL) at Purdue University. This laboratory is used only for economic experiments with an explicit no deception policy. The subject pool consisted of undergraduate students in the VSEEL subject database. Subjects may have participated in other economic experiments but not the specific treatments conducted for this paper. Nine sessions involving 170 subjects were conducted between MarchOctober 2013 under an approved IRB protocol. All payoffs are given in points and these points accumulate across periods. Points were converted into U.S. dollars at the rate of 30 points $=\$ 1$. This method of payment is fairly common in repeated game experiments (e.g. Bó (2005)). Average pay was slightly over 25 USD per-session, with a range from $\$ 15$ to $\$ 38$, which includes a 5 dollar show-up fee. We spent considerable time (usually 40-50 minutes) at the beginning of each session covering the instructions, control questions, and practice rounds. ${ }^{14}$ Moreover, we also wanted to have subjects play enough periods during the live periods to ensure that they had adequate time to learn. ${ }^{15}$ Consequently, the average session lasted about three hours in total, including instructions, questionnaire, trial periods, post experimental payouts and post experimental demographic questionnaire. Our average hourly payouts were consistent with average hourly rates of other experiments conducted in the same

\footnotetext{
${ }^{13}$ We recruited more subjects for the 0.5 treatments because the expected length of supergames are shorter. Thus, it was likely that we would have exhausted matches more frequently in the 0.5 sessions if we did not recruit more subjects. The differences in group size should not create an imbalance in group reputation effects since we implemented stranger matching.

${ }^{14}$ Instructions were typically read aloud with subjects following along using paper copies.

${ }^{15}$ We were fairly confident that subjects had become quite competent after some experience because, with the exception of one or two outliers per session, most were making trades fairly quickly after the first five or so initial periods.
} 
laboratory. All experiments were programmed with Z-tree (Fischbacher, 2007).

\section{$5 \quad$ Results}

We organize our results into three sections. In section 5.1, we report the analyses of the main testable implications that follow from Corollary 1 . In section 5.2, we examine the channels through which the main results might arise. Finally, section 5.3 focuses on strategic uncertainty which is important since incomplete contracts leave some parties with ex post discretionary latitude to deviate from the upfront agreement.

\subsection{Major Results.}

Corollary 1 delivers three major testable implications.

1. Prediction 1 : More complete contracts should be observed in the E treatment relative to the PE treatments.

2. Prediction 2: The use of complete contracts should increase with a drop in $\delta$; i.e. more complete contracts should be observed in PE0.50 relative to PE0.80.

3. Prediction 3 : The contracted level of quality, $Q$, decreases with a drop in $\delta$.

Figure 1 presents descriptive statistics of the fraction of complete contracts offered by treatment in graphical form. To clarify, this graph plots the average fraction of complete contracts for each period, using data from all sessions. Since the number and lengths of supergames differed across sessions and treatments, Figure 1 cannot distinguish the fraction of complete contracts across supergames. Nonetheless, the figure is useful in providing a picture of how play evolved as subjects gained experience. Going forward, all graphs plotted against periods can be interpreted similarly. 


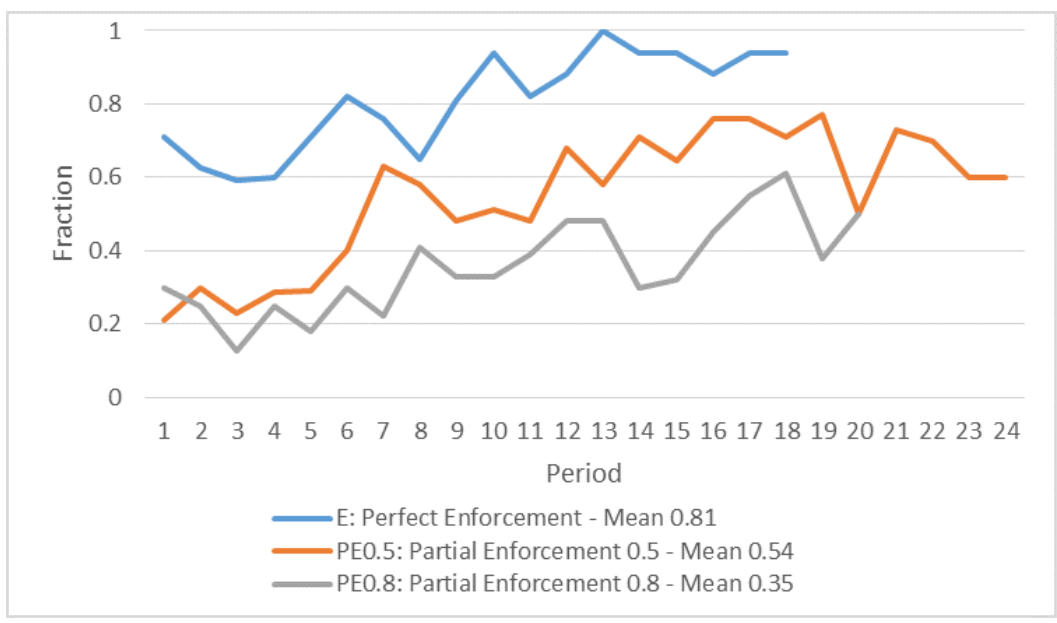

Figure 1: Average fraction of complete contracts across periods for all sessions.

Notice that the descriptive statistics are largely consistent with Predictions 1 and 2 in that the E-treatment yields a significantly higher fraction of complete contracts than either PE0.50 or PE0.80. The means are 0.81, 0.54 and 0.35, respectively, and the gaps appear to persist across almost all periods. Second, the fraction of complete contracts are higher in the PE0.50 treatment vs the PE0.80 treatment. In short, with partial enforcement, a large number of contract offers leave out even costlessly verifiable terms such as the contractible quality $Q=5$. This is especially true when the prospects of self-enforcement is stronger (i.e. in the 0.80 treatment). Intuitively, the subjects believe they can do better than $Q=5$ by informally contracting for some $Q>5$ as noted in Proposition 2 .

While the descriptive statistics in Figure 1 are useful for giving us an overview of the results, we also conduct formal hypothesis testing and robustness checks. Table 3 contains the results from six probit regressions, where the dependent variable takes the value of " 1 " if a binding complete contract is offered. The first three regressions contain a treatment dummy for PE which takes a value of "1" if the observation was either from PE0.50 or PE0.80. The base category is the E treatment and therefore the 
Table 3: Probability that Buyer Offers a Binding Contract (Probit marginal effects evaluated at means).

\begin{tabular}{|c|c|c|c|c|c|c|}
\hline VARIABLES & (1) & $(2)$ & (3) & $(4)$ & (5) & (6) \\
\hline$\overline{P E}$ (Treatment dummy) & $\begin{array}{c}-0.38^{* * *} \\
(0.08)\end{array}$ & $\begin{array}{c}-0.43^{* * *} \\
(0.08)\end{array}$ & $\begin{array}{c}-0.36^{* * *} \\
(0.005)\end{array}$ & & & \\
\hline PE0.50 (Treatment dummy) & & & & $\begin{array}{c}-0.31^{* * * *} \\
(0.07)\end{array}$ & $\begin{array}{c}-0.36^{* * *} \\
(0.07)\end{array}$ & $\begin{array}{c}-0.36^{* * *} \\
(0.006)\end{array}$ \\
\hline PE0.80 (Treatment dummy) & & & & $\begin{array}{c}-0.50^{* * *} \\
(0.07)\end{array}$ & $\begin{array}{c}-0.54^{* * *} \\
(0.09)\end{array}$ & $\begin{array}{c}-0.75^{* * *} \\
(0.01)\end{array}$ \\
\hline Period & & $\begin{array}{c}0.04^{* * *} \\
(0.01)\end{array}$ & $\begin{array}{c}0.05 * * * \\
(0.01)\end{array}$ & & $\begin{array}{c}0.05^{* * *} \\
(0.01)\end{array}$ & $\begin{array}{c}0.05 * * * \\
(0.01)\end{array}$ \\
\hline Period $^{2}$ & & $\begin{array}{c}-0.0009^{* *} \\
(0.0004)\end{array}$ & $\begin{array}{c}-0.0009 * * \\
(0.0004)\end{array}$ & & $\begin{array}{c}-0.001^{* *} \\
(0.0004)\end{array}$ & $\begin{array}{c}-0.001 \\
(0.0004)\end{array}$ \\
\hline Session fixed effects & No & No & Yes & No & No & Yes \\
\hline$\overline{P E 0.50-P E 0.80 \text { (diff in coefficients) }}$ & & & & $\begin{array}{c}0.19^{* * *} \\
(0.05)\end{array}$ & $\begin{array}{c}0.18^{* * *} \\
(0.06)\end{array}$ & $\begin{array}{c}0.39^{* * *} \\
(0.004)\end{array}$ \\
\hline pseudo $-R^{2}$ & 0.07 & 0.13 & 0.16 & 0.09 & 0.14 & 0.16 \\
\hline Obs. & 1348 & 1348 & 1348 & 1348 & 1348 & 1348 \\
\hline
\end{tabular}

sign of the marginal effect coefficient for PE gives us a test of Prediction 1. A negative sign would be consistent with the prediction since it suggests that the probability of a complete contract being offered decreases under partial enforcement. In regressions (2) and (3), we control for periods and session fixed effects. All regressions were estimated using robust standard errors adjusted for clustering on sessions.

One can see in columns (1)-(3) that the estimated marginal effect coefficients for the PE dummy are all negative and significantly different from zero. This finding suggests that we cannot reject Prediction 1. Additionally, the magnitude of the estimated marginal effects is fairly stable across the different specifications suggesting that our result is robust. Thus, it appears that our subjects are significantly more likely to omit costlessly verifiable terms under partial enforcement.

Regressions (4)-(6) separate the PE variable into PE0.50 and PE0.80, which allows us test Prediction 2. Under Prediction 2, the marginal effect of using a complete contract should be lower in PE0.80 relative to PE0.50. The estimated marginal effects are negative and the magnitude of the PE0.80 marginal effect is lower across all three specifications. We also test for the equality of the PE0.80 and PE0.50 marginal effects 
and report the estimated differences in the row labeled PE0.50-PE0.80. Consistent with Prediction 2, the marginal effect for PE0.80 is lower than that for PE0.50. The difference ranges from 0.18 to 0.39 depending on the specification. ${ }^{16}$

We next consider Prediction 3. Figure 2 plots the evolution of $Q$ for executed

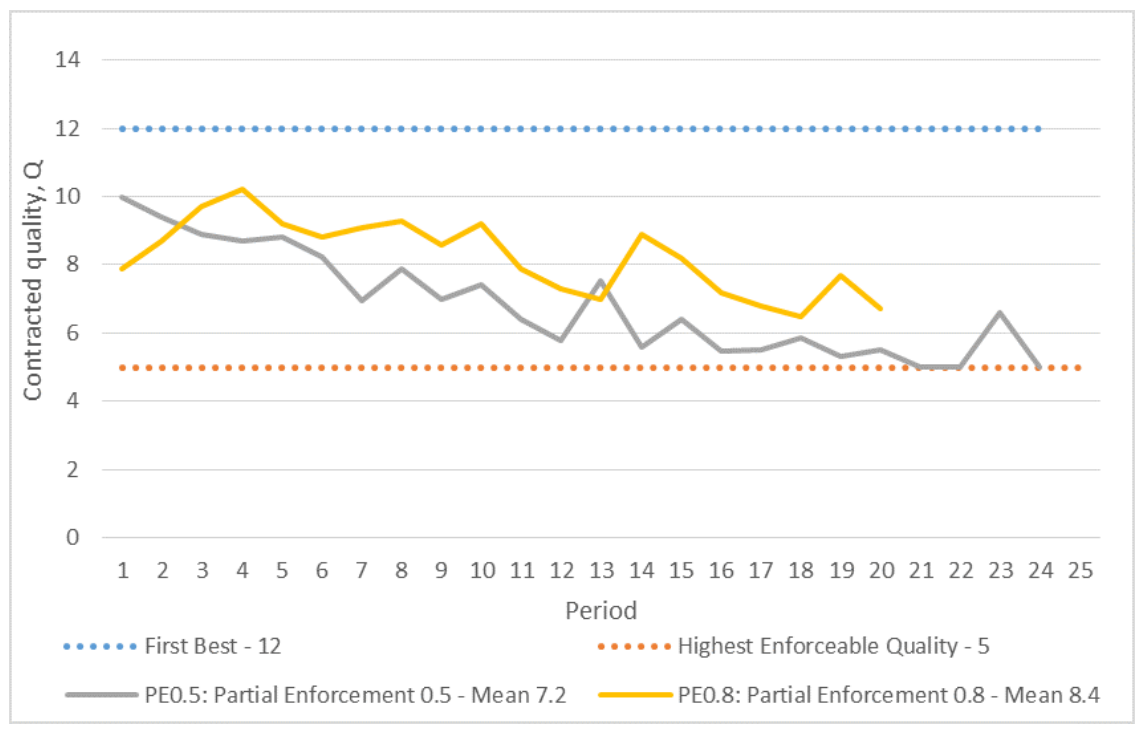

Figure 2: Average contracted level of quality, $Q$, of incomplete contracts across periods for all PE session trades.

trades across periods in the two PE treatments. One can see that the pattern is broadly consistent with Prediction 3 as average per-period $Q$ is higher in the PE0.80 treatment across most periods. The overall mean $Q$ in PE0.80 is 8.4 vs 7.2 in PE0.50. Table 4 presents the results of regressions used to test Prediction 3. Only the PE data were used with PE0.50 chosen as the base category. The regression results reveal that, consistent with Prediction 3, the coefficient for the PE0.80 dummy is significantly positive across all specifications.

\footnotetext{
${ }^{16}$ We also ran a similar probit regression using only the PE0.50 and PE0.80 data with a PE0.80 treatment dummy and PE0.50 as the omitted category. The estimated marginal effects for PE0.80 were identical to the "PE0.50-PE0.80 (diff in coefficients)" coefficients estimated in Table 3 so we did not report the results to conserve space.
} 
Table 4: Censored Regressions for Contracted Quality Requested by Buyer (PE data)

\begin{tabular}{|c|c|c|c|}
\hline VARIABLES & $(1)$ & $(2)$ & $(3)$ \\
\hline \multirow[t]{2}{*}{$\overline{P E 0.80 \text { (dummy) }}$} & $1.20^{* * *}$ & $1.01^{* * *}$ & $1.94^{* * *}$ \\
\hline & $(0.28)$ & $(0.35)$ & $(0.001)$ \\
\hline \multirow[t]{2}{*}{ Period } & & -0.20 & -0.18 \\
\hline & & $(0.14)$ & $(0.0 .14)$ \\
\hline \multirow[t]{2}{*}{ Period $^{2}$} & & 0.0005 & -0.0005 \\
\hline & & $(0.005)$ & $(0.005)$ \\
\hline Session fixed effects & No & No & Yes \\
\hline pseudo $-R^{2}$ & 0.007 & 0.03 & 0.03 \\
\hline Obs. & 672 & 672 & 672 \\
\hline
\end{tabular}

\subsection{Factors Affecting Major Results.}

In this section, we examine the channels through which we might potentially explain the major results. In principle, there are two major channels that might explain why a person might choose one type of contract over another: (1) the contract creates more surplus per-trade (quality closer to first best); and (2) the contract induces more trades (increase the odds that the contract will be accepted).

\subsubsection{How do complete contracts affect surplus per-trade?}

The key determinant of surplus per-trade is the actual quality level delivered by sellers. We compare these quality levels for each treatment under both complete and incomplete contracts.

In the perfect enforcement treatment E, we can see from Figure 3 that complete contracts implemented mean actual quality that is remarkably close to first best of 12 (11.7 vs 12). Moreover, $48 \%$ of trades resulted in exactly the first best level of quality. The few incomplete contracts that were used implemented an average of $q=7.14$ with only $5 \%$ implementing the first best level. Moreover, the incomplete contracts plot was volatile because there were so few trades using incomplete contracts. ${ }^{17}$

\footnotetext{
${ }^{17}$ In many periods, only one or two trades were executed using incomplete contracts. In the later periods, many did not use incomplete contracts at all. These are the observations for which the plot
} 


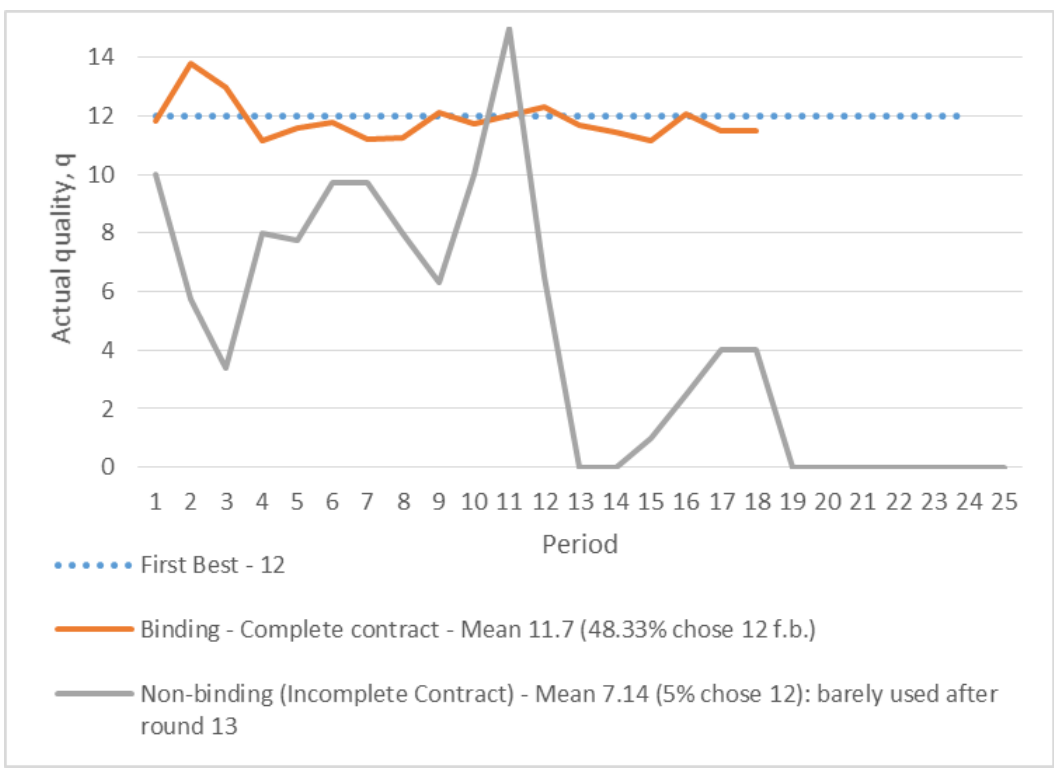

Figure 3: Average delivered quality, q, across periods for all E sessions.

To verify these graphical patterns, we also ran two censored regressions on quality (see regressions (1) and (2), Table 5) with lower and upper bounds of 1 and

Table 5: Censored Regressions for Actual Quality Delivered by Seller

\begin{tabular}{|c|c|c|c|c|c|c|}
\hline VARIABLES & $\begin{array}{c}(1) \\
\text { E data }\end{array}$ & $\begin{array}{c}(2) \\
\text { E data }\end{array}$ & $\begin{array}{c}(3) \\
\text { PE0.80 data }\end{array}$ & $\begin{array}{c}(4) \\
\text { PE0.80 data }\end{array}$ & $\begin{array}{c}(5) \\
\text { PE0.50 data }\end{array}$ & $\begin{array}{c}(6) \\
\text { PE0.50 data }\end{array}$ \\
\hline Binding (Complete contract dummy) & $\begin{array}{c}5.14^{* * *} \\
(1.14)\end{array}$ & $\begin{array}{c}5.60^{* * *} \\
(2.25)\end{array}$ & $\begin{array}{c}-1.86^{* * *} \\
(0.23)\end{array}$ & $\begin{array}{c}-2.37^{* * *} \\
(0.45)\end{array}$ & $\begin{array}{c}1.40 * * * \\
(0.23)\end{array}$ & $\begin{array}{c}2.00^{* * *} \\
(0.51)\end{array}$ \\
\hline Cooperated last period (dummy) & & $\begin{array}{l}1.72^{*} \\
(1.05)\end{array}$ & & $\begin{array}{l}2.28^{*} \\
(1.22)\end{array}$ & & $\begin{array}{c}0.25 \\
(0.65)\end{array}$ \\
\hline Cooperated last two periods (dummy) & & $\begin{array}{c}0.02 \\
(0.07)\end{array}$ & & $\begin{array}{l}-0.25 \\
(1.14)\end{array}$ & & $\begin{array}{c}0.02 \\
(0.38)\end{array}$ \\
\hline Period & $\begin{array}{l}-0.05 \\
(0.46)\end{array}$ & $\begin{array}{c}0.22 \\
(0.57)\end{array}$ & $\begin{array}{l}-0.06 \\
(0.07)\end{array}$ & $\begin{array}{c}-0.43^{* * *} \\
(0.13)\end{array}$ & $\begin{array}{c}-0.26^{* * *} \\
(0.05)\end{array}$ & $\begin{array}{c}-0.31^{* *} \\
(0.15)\end{array}$ \\
\hline Period $^{2}$ & $\begin{array}{l}-0.002 \\
(0.002)\end{array}$ & $\begin{array}{l}-0.01 \\
(0.02)\end{array}$ & $\begin{array}{c}0.003 \\
(0.005)\end{array}$ & $\begin{array}{c}0.02^{* * * *} \\
(0.003)\end{array}$ & $\begin{array}{c}0.007^{* * *} \\
(0.001)\end{array}$ & $\begin{array}{c}0.007 \\
(0.006)\end{array}$ \\
\hline Session fixed effects & Yes & Yes & Yes & Yes & Yes & Yes \\
\hline pseudo $-R^{2}$ & 0.07 & 0.12 & 0.01 & 0.03 & 0.01 & 0.03 \\
\hline Obs. & 221 & 160 & 304 & 111 & 368 & 85 \\
\hline
\end{tabular}

15, respectively, while controlling for periods and session fixed effects. Additionally, whether sellers will deliver high quality also depends on whether the two parties have successfully cooperated in the past. Regression (2) controls for whether both parties touched zero quality. 
cooperated last period and cooperated last two periods, where these dummy variables equal "1" if neither party shirked on their agreement last period and for the last two consecutive periods, respectively. Note that "shirking" implies that either the seller delivered $q<Q$ and/or the buyer made a bonus payment $b<B$. The estimated coefficient for the complete contracts dummy (Binding) is significantly positive. The magnitude of the coefficient does not vary much across the specifications. In short, complete contracts in the perfect enforcement regime delivered higher mean quality that is close to first best and resulted in less strategic uncertainty.

Figure 4 allows us to make the same comparison for the PE0.80 partial enforcement

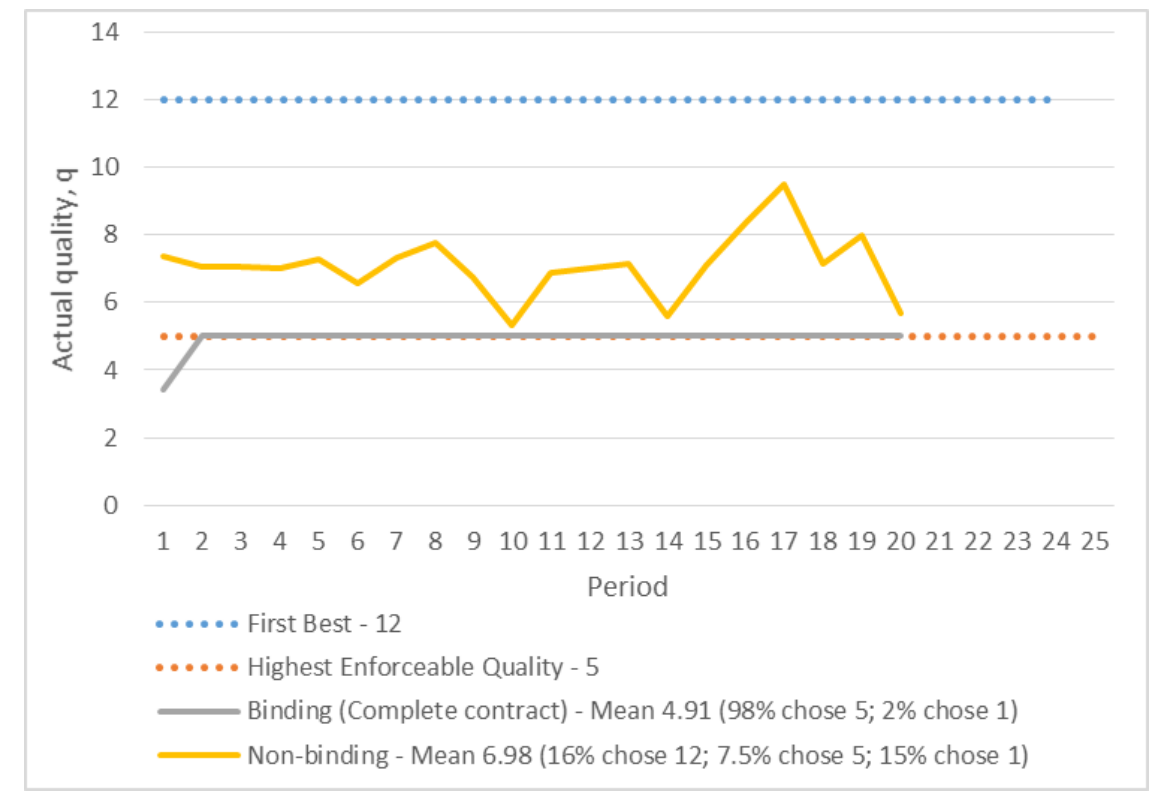

Figure 4: Average delivered quality, $q$, across periods for all PE0.80 sessions.

regime. Recall that the maximum contractible quality here is $Q_{f}=5$ which we plot in the lower dotted line in the figure. Recall from Figure 1 that only $35 \%$ of the contracts in this treatment are complete. Figure 4 reveals that the average quality is only $q=4.91$ under complete contracts and $q=6.98$ under incomplete contracts with $16 \%$ choosing the first best level of 12 . On the other hand, $15 \%$ of sellers chose 
minimum quality of $q=1$ suggesting that, even with a high discount factor, there is still significant strategic uncertainty. Regressions (3) and (4) in Table 5 suggests that delivered quality is lower under complete contracts relative to incomplete contracts. The Binding coefficient is -1.86 in regression (3) and -2.37 in regression (4), which controls for cooperation in the last two periods.

Figure 5 reports similar results for PE0.50. Average delivered quality is almost

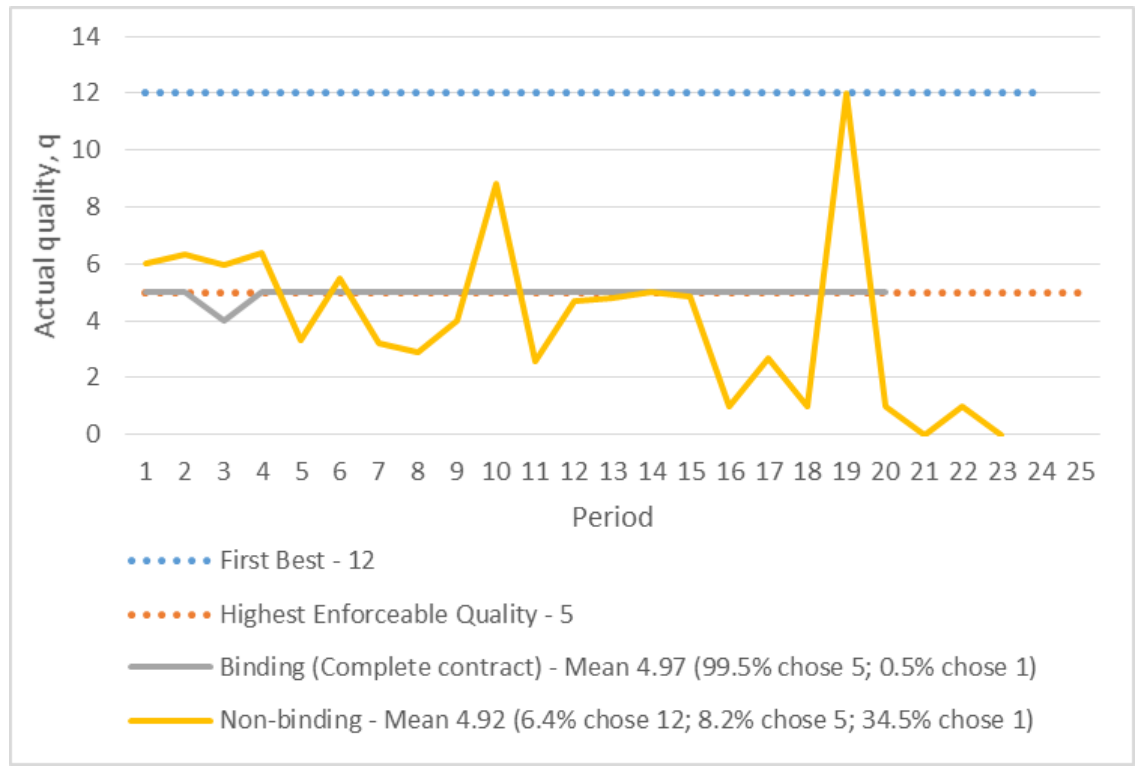

Figure 5: Average delivered quality, $q$, across periods for all PE0.50 sessions.

identical between the complete and incomplete contracts. However, regressions (5) and (6) in Table 5 show that, after controlling for other factors, complete contracts actually deliver higher quality. In regression (5), the coefficient for Binding is 1.40 while in regression (6), which controls for cooperation in prior periods, the coefficient is 2.00. Additionally, there is considerably more strategic uncertainty under incomplete contracts as $34.5 \%$ of trades resulted in $q=1$. Thus, it is not surprising that more complete contracts were used under PE0.50 relative to PE0.80. 


\subsubsection{How do complete contracts affect willingness of sellers to accept contracts across treatments?}

A second major determinant of surplus is the willingness of subjects to trade in the first place. From the buyer's perspective, creating surplus can only occur if sellers accept their contracts. Table 6 reports probit marginal effects for a dependent variable that takes a value of "1" if a seller rejected an offer and "0" if the seller accepted Table 6: Probability that Seller Rejects a Complete Contract (Probit marginal effects evaluated at means).

\begin{tabular}{|c|c|c|c|c|c|c|}
\hline VARIABLES & $\begin{array}{c}(1) \\
\text { E data }\end{array}$ & $\begin{array}{c}(2) \\
\text { E data }\end{array}$ & $\begin{array}{c}(3) \\
\text { PE0.80 data }\end{array}$ & $\begin{array}{c}(4) \\
\text { PE0.80 data }\end{array}$ & $\begin{array}{c}(5) \\
\text { PE0.50 data }\end{array}$ & $\begin{array}{c}(6) \\
\text { PE0.50 data }\end{array}$ \\
\hline Binding (Complete contract dummy) & $\begin{array}{l}0.012 \\
(0.06)\end{array}$ & $\begin{array}{c}0.03 \\
(0.06)\end{array}$ & $\begin{array}{c}0.11^{* *} \\
(0.04)\end{array}$ & $\begin{array}{c}0.07 \\
(0.06)\end{array}$ & $\begin{array}{c}-0.02 \\
(0.05)\end{array}$ & $\begin{array}{c}-0.1 \\
(0.19)\end{array}$ \\
\hline Cooperated last period (dummy) & & $\begin{array}{c}-0.41^{* * *} \\
(0.02)\end{array}$ & & $\begin{array}{c}-0.13^{* * *} \\
(0.04)\end{array}$ & & $\begin{array}{c}-0.25^{* *} \\
(0.11)\end{array}$ \\
\hline Cooperated last two periods (dummy) & & $\begin{array}{c}0.17^{* * *} \\
(0.02)\end{array}$ & & $\begin{array}{c}-0.26^{* * *} \\
(0.10)\end{array}$ & & $\begin{array}{l}-0.26 \\
(0.30)\end{array}$ \\
\hline Period & $\begin{array}{l}-0.01 \\
(0.02)\end{array}$ & $\begin{array}{l}-0.05 \\
(0.04)\end{array}$ & $\begin{array}{c}0.02 \\
(0.02)\end{array}$ & $\begin{array}{c}0.06^{* * * *} \\
(0.008)\end{array}$ & $\begin{array}{c}0.01 \\
(0.02)\end{array}$ & $\begin{array}{c}0.05 \\
(0.06)\end{array}$ \\
\hline Period $^{2}$ & $\begin{array}{l}-0.0003 \\
(0.0008)\end{array}$ & $\begin{array}{c}0.002 \\
(0.001)\end{array}$ & $\begin{array}{l}-0.0004 \\
(0.0009)\end{array}$ & $\begin{array}{c}-0.002^{* * *} \\
(0.0003)\end{array}$ & $\begin{array}{r}-0.0002 \\
(0.001)\end{array}$ & $\begin{array}{l}-0.001 \\
(0.002)\end{array}$ \\
\hline Session fixed effects & Yes & Yes & Yes & Yes & Yes & Yes \\
\hline$\overline{\text { pseudo }-R^{2}}$ & 0.08 & 0.25 & 0.03 & 0.11 & 0.01 & 0.15 \\
\hline Obs. & 302 & 201 & 426 & 166 & 620 & 149 \\
\hline
\end{tabular}

the offer. ${ }^{18}$ We are primarily interested in investigating whether complete contracts increase acceptance rates. The regressions in columns (1)-(2) examine treatment E, columns (3)-(4) examine treatment PE0.80, and columns (5)-(6) examine treatment PE0.50. Additionally, each pair of regressions for each treatment differ in whether the cooperation dummies are included or not.

For the most part, the estimated marginal effects for Binding suggests that a complete contract had little impact on a seller's willingness to reject in treatments $\mathrm{E}$

\footnotetext{
${ }^{18}$ We also created figures for the evolution of the fraction of rejected contracts across periods, but unlike the previous figures, these figures did not yield clear patterns that facilitated reader understanding. Therefore, we omitted them to conserve space.
} 
and PE0.50. ${ }^{19}$ These results suggest that contract acceptance would not be a major factor in buyer's use of complete vs incomplete contracts. However, regression (3) for the PE0.80 treatment does estimate a positive marginal effect of 0.11 suggesting that sellers are more likely to reject complete contracts in this treatment. However, once we add the cooperation dummies as in regression (4), the marginal effect for Binding is no longer significantly different from zero. Overall, these results suggest that a complete contract in itself has little impact on sellers' willingness to accept contracts. This is not surprising as buyers are likely to adjust equilibrium offers to satisfy sellers' participation constraints under both binding and non-binding contracts. What is interesting is that the cooperation dummy marginal effects in regressions (2), (4), and (6) suggest that a key determinant for contract acceptance is whether the buyer and seller successfully cooperated in the previous period or in the previous two periods (regression (4)). This is consistent with intuition as successful past trading can reduce strategic uncertainty for the trading parties. ${ }^{20}$

\footnotetext{
${ }^{19}$ We did not include other contract terms in the regression because then the estimated marginal effect on Binding would be interpreted as holding other contract terms constant. But this is rather unrealistic as contract terms for complete and incomplete contracts are likely to vary significantly. Thus, the interpretation of the Binding marginal effect holding other contract terms constant would be nonsensical. Nonetheless, while not reported in this paper, we did do a robustness check and ran regressions that included the other contract variables. While the binding coefficient for the $\mathrm{E}$ data became positive and significant (controlling for the lagged cooperation variables), it remained not significantly different from zero for both the PE0.80 and PE0.50 data at the 5\% significance level.

${ }^{20}$ The one exception is the positive marginal effect for the "Cooperated last two periods" dummy in regression (2). It is rather odd that rejection might increase after successfully cooperating over the last two periods, but since the $\mathrm{E}$ treatment is unique in that the parties can completely eliminate strategic uncertainty while generating high surplus, it is possible that a rejection might signal a desire to switch to a complete contract.
} 


\subsection{Determinants of strategic uncertainty under incomplete contracts.}

There are two major types of strategic uncertainty faced by buyers under incomplete contracts. First, the seller can reject a given contract offer. Second, even if the seller accepts, the seller might not deliver $q \geq Q$. The key theoretical determinants of the rejection decision are the participation and credibility constraints. To explain the latter constraint, note that the principal's (buyer's) self-enforcement constraints 4 and 5 can be combined and rewritten as:

$\delta\left[r(Q)-P-\alpha \pi_{f}^{N_{A}}-(1-\alpha) \bar{\pi}\right] \geq B \geq(1-\delta)[c(Q)-c(\underline{q})]-\delta\left[P-c(Q)-\alpha u_{f}^{N_{A}}-(1-\alpha) \bar{u}\right]$

The above bounds on $B$ are more useful than the bounds identified in Proposition 1 for empirical analysis because, while the optimal contract suggests that sellers (agents) are paid no rents and held at their reservation utility, many of our buyers did leave sellers with rents. When sellers earn rents, the promise of continued rents can substitute for $B$ in providing incentives. Therefore, inequality 7 adjusts the bounds for cases when sellers earn rents. For example, the right-hand-side bound is relaxed when sellers earn rents because $B$ need not be as high to incent sellers to deliver $q \geq Q$. This constraint along with the seller's participation constraint 2 can conceptualize the two types of strategic uncertainty faced by buyers. Specifically:

- The seller is more likely to reject a contract if $B$ is not credible (too large) and/or his participation constraint is not satisfied.

- The seller is more likely to shirk $(q<Q)$ if $B$ is not incentive compatible.

We used the upper and lower bounds in equation 7 to create two additional dummy variables. The variable noncredible $B$ refers to a dummy that takes a value of "1" if 
a promised $B$ offer is greater than the upper bound. The variable nonIC $B$ refers to a dummy that takes a value of "1" if a promised $B$ offer is less than the lower bound so that it is not incentive compatible for the seller to deliver $q \geq Q$. We also created a dummy variable Participation satisfied that takes the value of "1" if the promised profit to the seller under a contract exceeds the seller's reservation utility.

The first regression in Table 7 examines the seller's rejection decision. The depenTable 7: Probit Marginal Effects for Strategic Uncertainy in Incomplete Contracts (All PE data)

\begin{tabular}{|c|c|c|c|}
\hline VARIABLES & $\begin{array}{c}(1) \\
\text { Seller Reject }\end{array}$ & $\begin{array}{c}(2) \\
\text { Seller Shirk }\end{array}$ & $\begin{array}{c}(3) \\
\text { Buyer Shirk }\end{array}$ \\
\hline noncredible $B$ (dummy) & $\begin{array}{c}0.40^{* *} \\
(0.20)\end{array}$ & & $\begin{array}{c}0.24^{* * *} \\
(0.09)\end{array}$ \\
\hline nonIC B (dummy) & & $\begin{array}{c}0.52^{* * *} \\
(0.08)\end{array}$ & \\
\hline Participation satisfied (dummy) & $\begin{array}{c}-0.47^{* *} \\
(0.23)\end{array}$ & & \\
\hline Cooperated last period (dummy) & $\begin{array}{c}-0.31^{* * *} \\
(0.12)\end{array}$ & $\begin{array}{l}-0.20 \\
(0.14)\end{array}$ & $\begin{array}{l}-0.20 \\
(0.23)\end{array}$ \\
\hline Cooperated last two periods (dummy) & $\begin{array}{l}-0.13 \\
(0.09)\end{array}$ & $\begin{array}{l}-0.04 \\
(0.20)\end{array}$ & $\begin{array}{c}-0.22^{*} \\
(0.12)\end{array}$ \\
\hline Period & $\begin{array}{c}0.04 \\
(0.04)\end{array}$ & $\begin{array}{c}0.02 \\
(0.03)\end{array}$ & $\begin{array}{l}-0.06 \\
(0.04)\end{array}$ \\
\hline Period $^{2}$ & $\begin{array}{c}-0.0006 \\
(0.001)\end{array}$ & $\begin{array}{l}0.0002 \\
(0.001)\end{array}$ & $\begin{array}{l}0.003^{* *} \\
(0.0015)\end{array}$ \\
\hline Session fixed effects & Yes & Yes & Yes \\
\hline pseudo- $R^{2}$ & 0.24 & 0.28 & 0.31 \\
\hline Obs. & 157 & 98 & 98 \\
\hline
\end{tabular}

dent variable takes a value of " 1 " if the seller rejects a contract. One can see that the probability of rejection declines when the participation constraint is satisfied $(-0.47$, $p<0.05)$. In addition, the marginal effect for noncredible $B$ is positive $(0.40)$ and significantly different from zero, suggesting that sellers reject contracts if the buyer offers a non-credible bonus that seems too good to be true. Moreover, the estimated coefficients for the two cooperation dummies suggest that the probability of rejection declines if the buyer and seller traded successfully, with neither party shirking, in the past. The second regression(column 2) examines the seller's shirk decision (depen- 
dent variable $=1$ if $q<Q$ ). The marginal effect for nonIC B is positive and significant $(0.52, p<0.001)$ suggesting that a non-incentive compatible bonus does a poor job of getting the seller to honor his agreement. Both columns (1) and (2) report results that are consistent with the theory of relational contracting.

Turning now to the strategic uncertainty the seller faces, the key issue is whether the buyer will honor the discretionary bonus that was promised; i.e. whether the buyer will deliver $b \geq B$. The key theoretical determinant is whether the promised $B$ breaches the upper bound of inequality 7 . If it breaches, then the buyer's discounted future rents do not offset the gains from shirking in the current period. Regression (3) shows that the estimated marginal effect for noncredible $B$ is 0.24 and significantly different from zero at the $1 \%$ level of significance. Hence, there is support for the theory that buyers will shirk on non-credible bonuses.

\section{Conclusion}

Our results suggest that the contract enforcement institutional environment can profoundly impact the types of contracts people choose. When perfect third-party enforcement is available, fully complete contracts are the most efficient and widely chosen contracts by our subjects to execute trades. However, with only partial third-party enforcement, many subjects strategically switched to incomplete contracts, though this also increased their exposure to strategic uncertainty. Incomplete contracts combined with a strong prospect of self-enforcement allowed parties to generate higher average joint surplus than the best available complete contract in an imperfect enforcement environment. Finally, we find that strategic uncertainty and counterparty risk tends to increase when discretionary components of incomplete contracts are not credible or non-incentive compatible. That is, if principals offered unusually high 
discretionary bonuses that violate their self-enforcement constraints, agents tend to reject contracts. Even if accepted, principals tend to shirk on paying these bonuses. On the other hand, if offered bonuses were too low and violated the agents' selfenforcement constraints, agents shirked on providing contracted levels of quality.

Our study contributes to the emerging literature on "second generation" models of incomplete contracts based on relational contracting and endogenous incompleteness (Aghion and Holden, 2011). This work also provides another basis for explaining the empirical pattern identified by Scott (2003) among contracts litigated in U.S. courts where parties intentionally omit costlessly verifiable contractual elements.

Our findings also suggest that legal or regulatory interventions to improve contracting institutions might enhance efficiency and reduce strategic uncertainty, but only if perfect verifiability can be achieved. If only partial verifiability and enforcement can be achieved, then the issue becomes much more subtle and complex. Partial verifiability might improve contracting outcomes depending on the degree to which parties can self-enforce incomplete contracts. One can also imagine a scenario in which an incremental improvement in partial enforcement can cause existing relational contracts to unravel which might decrease welfare if the best available complete contracts do not perform as well as the relational contracts that they replaced. Future research should examine this question in more depth.

Our experiments also generated sufficiently rich data that might allow for an indepth analysis of the types of strategies people play and/or how contracting parties altered or renegotiated their contracts after one or both parties shirked. The literature on repeated games and relational contracts suggests that there are numerous strategies people can play. For instance, it might be of interest to understand whether people break off trade following a deviation (an inefficient punishment) versus using an expanded relational contract that simply reallocated surplus away from the de- 
viator while maintaining cooperation (an efficient punishment). These issues might warrant a separate paper. Finally, there are additional comparative statics predictions that can be explored, such as exogenous changes in revenues or costs, which would allow us to examine the impact of demand or technology shocks on endogenous incompleteness.

\section{References}

Aghion, P. and R. Holden (2011). Incomplete contracts and the theory of the firm: What have we learned over the past 25 years? The Journal of Economic Perspectives 25, 181-197.

Akerlof, G. (1982). Labor contracts as partial gift exchange. The Quarterly Journal of Economics 97(4), 543-569.

Baker, G., R. Gibbons, and K. Murphy (1994). Subjective performance measures in optimal incentive contracts. Quarterly Journal of Economics 109, 1125-1156.

Battigalli, P. and G. Maggi (2002). Rigidity, discretion, and the costs of writing contracts. American Economic Review, 798-817.

Battigalli, P. and G. Maggi (2008). Costly contracting in a long-term relationship. The RAND Journal of Economics 39(2), 352-377.

Bernheim, B. and M. Whinston (1998). Incomplete contracts and strategic ambiguity. American Economic Review, 902-932.

Bó, P. D. (2005). Cooperation under the shadow of the future: experimental evidence from infinitely repeated games. American Economic Review, 1591-1604. 
Boot, A., S. Greenbaum, and A. Thakor (1993). Reputation and discretion in financial contracting. American Economic Review, 1165-1183.

Brown, M., A. Falk, and E. Fehr (2004). Relational contracts and the nature of market interactions. Econometrica 72(3), 747-780.

Dixit, A. K. (2007). Lawlessness and Economics: Alternative Modes of Governance. Princeton University Press.

Fehr, E. and A. Falk (1999). Wage rigidity in a competitive incomplete contract market. Journal of Political Economy 107(1), 106-134.

Fehr, E. and S. Gächter (2000). Fairness and retaliation: The economics of reciprocity. The Journal of Economic Perspectives, 159-181.

Fehr, E., S. Gächter, and G. Kirchsteiger (1997). Reciprocity as a contract enforcement device: Experimental evidence. Econometrica, 833-860.

Fehr, E., A. Klein, and K. Schmidt (2007). Fairness and contract design. Econometrica $75(1), 121-154$.

Fischbacher, U. (2007). z-tree: Zurich toolbox for ready-made economic experiments. Experimental Economics 10(2), 171-178.

Halac, M. (2012). Relational contracts and the value of relationships. American Economic Review 102, 750-779.

Hart, O. (1995). Firms, Contracts and Financial Structure. Oxford University Press.

Klein, B. and K. Leffler (1981). The role of market forces in assuring contractual performance. The Journal of Political Economy, 615-641. 
Kvaløy, O. and T. Olsen (2009). Endogenous verifiability and relational contracting. American Economic Review 99(5), 2193-2208.

Levin, J. (2003). Relational incentive contracts. The American Economic Review 93(3), 835-857.

MacLeod, W. (2007). Reputations, relationships, and contract enforcement. Journal of Economic Literature, 595-628.

MacLeod, W. and J. Malcomson (1989). Implicit contracts, incentive compatibility, and involuntary unemployment. Econometrica, 447-480.

Scott, R. (2003). Theory of self-enforcing indefinite agreements. Colum. Law Review 103, 1641.

Shapiro, C. and J. Stiglitz (1984). Equilibrium unemployment as a worker discipline device. American Economic Review 74, 433-444.

Sloof, R. and J. Sonnemans (2011). The interaction between explicit and relational incentives: An experiment. Games and Economic Behavior 73, 573-594.

Tirole, J. (1999). Incomplete contracts: Where do we stand? Econometrica 67(4), $741-781$.

Yang, H. (2013). Nonstationary relational contracts with adverse selection. International Economic Review 54(2), 525-547. 


\section{Appendix A}

\section{Proof of Lemma 1}

Proof. Let the mesh of a partition $E_{A}=\left\{e_{A 1}, \ldots, e_{A N_{A}}\right\}$ of $A_{A}$ be denoted by $\hat{e}_{A n}=$ $\max _{n \in\left\{1, N_{A}\right\}}\left|q_{n+1}-q_{n}\right|$. By Definition 1, $\hat{e}_{A n}$ is decreasing in $N_{A}$. Thus, for any $\epsilon>0$, there exists some $N_{\epsilon}$ such that for $N_{A}>N_{\epsilon}, \max _{n \in\left\{1, N_{A}\right\}}\left|q_{n+1}-q_{n}\right|<\epsilon$. Therefore, it must be true that every subinterval of the partition has a length that is less than $\epsilon$ for $N_{A}>N_{\epsilon}$.

Let $E_{A_{\epsilon}}$ be a partition of $A_{A}$ with $N_{A}>N_{\epsilon}$. Note that $q^{*}$ belongs to some subinterval $e_{A n} \in E_{A_{\epsilon}}$ with length $\left|q_{n+1}-q_{n}\right|$ and a contractible quality level $\underline{q_{n}}=q_{n}$. Therefore, by Definition 2, the minimum distance that $q^{*}$ is from a contractible quality level in the contractible set $\underline{E_{A_{\epsilon}}}$ can be denoted $\left|\underline{q_{f_{\epsilon}}}-q^{*}\right|=\min \left\{\left|\underline{q_{n+1}}-q^{*}\right|,\left|\underline{q_{n}}-q^{*}\right|\right\}$. Since $\left|\underline{q_{f_{\epsilon}}}-q^{*}\right|<\left|q_{n+1}-q_{n}\right|$, it follows that $\left|\underline{q_{f_{\epsilon}}}-q^{*}\right|<\left|q_{n+1}-q_{n}\right| \leq \max _{n \in\left\{1, N_{A}\right\}}\left|q_{n+1}-q_{n}\right|<$ $\epsilon$.

\section{Proof of Lemma 2}

Proof. By Lemma 1, there exists a contractible quality level $q_{f_{\epsilon}}$ such that $\lim _{N_{A} \rightarrow \infty} q_{f_{\epsilon}}=$ $q^{*}$. Since the surplus function $S(q)=r(q)-c(q)-\bar{u}-\bar{\pi}$ is continuous in $q$ by assumption, it must be the case that $\lim _{N_{A} \rightarrow \infty} S\left(q_{f_{\epsilon}}\right)=S\left(q^{*}\right)$. Moreover, since $q_{f}^{N_{A}}$ is the contractible quality level that yields the highest surplus among all contractible quality levels, it must be the case that $S\left(q^{*}\right) \geq S\left(q_{f}^{N_{A}}\right) \geq S\left(q_{f_{\epsilon}}\right)$ for all $N_{A}$. Therefore, we also have $\lim _{N_{A} \rightarrow \infty} S\left(q_{f}^{N_{A}}\right)=S\left(q^{*}\right)$ 


\section{Proof of Proposition 1}

Proof. First note that with stationary contracts, this essentially becomes a static problem since $V(C)=r(Q)-P-B$ at the optimal self-enforcing values of $(Q, P, B)$. Second, note that 4 and 5 can be combined to get:

$\frac{\delta}{1-\delta}\left[V(C)-\alpha \pi_{f}^{N_{A}}-(1-\alpha) \bar{\pi}\right] \geq B \geq[c(Q)-c(\underline{q})]-\frac{\delta}{1-\delta}\left[U(C)-\alpha u_{f}^{N_{A}}-(1-\alpha) \bar{u}\right]$

This provides a very intuitive look at the self-enforcement conditions. Essentially, 8 says that the promised unenforceable bonus has to be large enough to prevent the agent from shirking; i.e. it must cover the cost difference between honoring the agreement by producing $Q$ and the most profitable shirk which is to produce minimum quality $q$ minus future discounted surplus that the agent gets from the relationship. Conversely, for the promised bonus to be credible, it cannot be so large that it exceeds the discounted rents that the principal receives from the relationship. If the promised bonus is not credible, the agent will not believe that it will be paid. Additionally, 8 can be rearranged to get:

$$
\frac{\delta}{1-\delta}\left[r(Q)-c(Q)-\alpha \pi_{f}^{N_{A}}-(1-\alpha) \bar{\pi}-\alpha u_{f}^{N_{A}}-(1-\alpha) \bar{u}\right] \geq c(Q)-c(\underline{q})
$$

Given the assumptions that $r^{\prime}(Q) \geq 0, r^{\prime \prime}(Q) \leq 0, c^{\prime}(Q)>0$, and $c^{\prime \prime}(Q) \geq 0,9$ tightens as $Q$ increases. Suppose that $\hat{Q}$ is the value of $Q$ at which 9 holds with equality. Then if $Q^{*}>\hat{Q}$, then $Q^{*}$ is not implementable. However, if $Q^{*} \leq \hat{Q}$, then $Q^{*}$ can be implemented. Therefore, the principal can only contract for some $\tilde{Q} \leq Q^{*}$.

To derive the optimal payment scheme, we must consider two cases. First, if $\hat{Q} \geq Q^{*}$ so that the principal can contract for the first best level of quality where $r^{\prime}\left(Q^{*}\right)=c^{\prime}\left(Q^{*}\right)$, then there is slack in 8. Second, if $\hat{Q}<Q^{*}$ so $r^{\prime}(\hat{Q})>c^{\prime}(\hat{Q})$, then 
the principal will contract for $\tilde{Q}=\hat{Q}$ and 8 binds with equality. We will analyze each case separately.

Case 1: $\hat{Q} \geq Q^{*}$ : Because there is slack in 8 , for a given $\tilde{Q}$ the principal has the freedom to offer a $B(\tilde{Q})$ in the interval $\frac{\delta}{1-\delta}\left[V(C)-\alpha \pi_{f}^{N_{A}}-(1-\alpha) \bar{\pi}\right] \geq B \geq$ $[c(Q)-c(\underline{q})]-\frac{\delta}{1-\delta}\left[U(C)-\alpha u_{f}^{N_{A}}-(1-\alpha) \bar{u}\right]$. To show that any $B(\tilde{Q})$ in this interval leads to the same first best $Q^{*}$, we analyze the two cases where $B(\tilde{Q})$ equals the extreme values in the interval and show that they both lead to the principal implementing $Q^{*}$. That is, we analyze the cases $B^{H}(\tilde{Q})=\frac{\delta}{1-\delta}\left[V(C)-\alpha \pi_{f}^{N_{A}}-(1-\alpha) \bar{\pi}\right]$ and $B^{L}(\tilde{Q})=[c(Q)-c(\underline{q})]-\frac{\delta}{1-\delta}\left[U(C)-\alpha u_{f}^{N_{A}}-(1-\alpha) \bar{u}\right]$ separately and show that they both implement $Q^{*}$. Then it would not be difficult to show that any linear combination $\bar{B}(\tilde{Q})=k B^{H}(\tilde{Q})+(1-k) B^{L}(\tilde{Q})$ for $k \in(0,1)$ also allows the principal to implement $Q^{*}$.

Subcase (1A): $B=\frac{\delta}{1-\delta}\left[V(C)-\alpha \pi_{f}^{N_{A}}-(1-\alpha) \bar{\pi}\right]$ $B=\frac{\delta}{1-\delta}\left[V(C)-\alpha \pi_{f}^{N_{A}}-(1-\alpha) \bar{\pi}\right]$ can be rewritten as:

$$
B=\delta\left\{r(Q)-P-\alpha \pi_{f}^{N_{A}}-(1-\alpha) \bar{\pi}\right\}
$$

We can plug 10 into the objective function and write the principal's optimization problem in Langrangian form as:

$$
\begin{gathered}
\max _{Q, P, B} L=r(Q)-P-\delta\left\{r(Q)-P-\alpha \pi_{f}^{N_{A}}-(1-\alpha) \bar{\pi}\right\} \\
+\lambda\left\{P+\delta\left[r(Q)-P-\alpha \pi_{f}^{N_{A}}-(1-\alpha) \bar{\pi}\right]-c(Q)-\alpha u_{f}^{N_{A}}-(1-\alpha) \bar{u}\right\}
\end{gathered}
$$

where $\lambda$ is the Langrange multiplier for the agent's participation constraint. 
Taking partial derivatives, the Kuhn-Tucker conditions are:

$$
\begin{gathered}
r^{\prime}(Q)-\delta r^{\prime}(Q)+\lambda\left\{\delta r^{\prime}(Q)-c^{\prime}(Q)\right\} \leq 0 \\
-1+\delta+\lambda[1-\delta] \leq 0
\end{gathered}
$$

Subsubcase (1Ai): $\lambda>0$

This case implies that the participation constraint is binding and therefore $P$ cannot be lowered without bound. Thus, 13 implies that $\lambda=1$, which in turns implies that 12 is $r^{\prime}(\tilde{Q})=c^{\prime}(\tilde{Q})$. Thus, it must be true that $\tilde{Q}=Q^{*}$.

To solve for $\tilde{P}$ use the participation constraint $P+B(\tilde{Q})-c(\tilde{Q})=\alpha u_{f}^{N_{A}}+(1-$ $\alpha) \bar{u}$. Plug $B(\tilde{Q})=\delta\left\{r(\tilde{Q})-P-\alpha \pi_{f}^{N_{A}}-(1-\alpha) \bar{\pi}\right\}$ in and then solve for $P$ to get $\tilde{P}=\frac{\alpha u_{f}^{N_{A}}+(1-\alpha) \bar{u}+c(\tilde{Q})}{1-\delta}-\frac{\delta}{1-\delta}\left\{r(\tilde{Q})-\delta \pi_{f}^{N_{A}}-(1-\delta) \bar{\pi}\right\}$. Now plugging $\tilde{P}$ back into $B(\tilde{Q})=\delta\left\{r(\tilde{Q})-P-\alpha \pi_{f}^{N_{A}}-(1-\alpha) \bar{\pi}\right.$ yields $B(\tilde{Q})=\frac{\delta}{1-\delta}\left\{r(\tilde{Q})-c(\tilde{Q})-\delta \pi_{f}^{N_{A}}-\right.$ $\left.(1-\delta) \bar{\pi}-\alpha u_{f}^{N_{A}}-(1-\alpha) \bar{u}\right\}$. Therefore, the optimal contract is characterized by:

$$
\begin{gathered}
r^{\prime}(\tilde{Q})=c^{\prime}(\tilde{Q}) \text { where } \tilde{Q}=Q^{*} \\
\tilde{P}^{H}=\frac{\alpha u_{f}^{N_{A}}+(1-\alpha) \bar{u}+c(\tilde{Q})}{1-\delta}-\frac{\delta}{1-\delta}\left\{r(\tilde{Q})-\alpha \pi_{f}^{N_{A}}-(1-\alpha) \bar{\pi}\right\} \\
B^{H}(\tilde{Q})=\frac{\delta}{1-\delta}\left\{r(\tilde{Q})-c(\tilde{Q})-\alpha \pi_{f}^{N_{A}}-(1-\alpha) \bar{\pi}-\alpha u_{f}^{N_{A}}-(1-\alpha) \bar{u}\right\}
\end{gathered}
$$

Subsubcase (1Aii): $\lambda=0$

The K-T condition 12 and 13 imply that $r^{\prime}(Q)[1-\delta] \leq 0$ or $r^{\prime}(Q) \leq 0$. However, this contradicts the assumption that $r^{\prime}(Q)>0$ for all feasible $Q$. Therefore, this case is ruled out and the participation constraint must bind.

Subcase (1B): $B=c(Q)-c(\underline{q})-\frac{\delta}{1-\delta}\left[P+B-c(Q)-\alpha u_{f}^{N_{A}}-(1-\alpha) \bar{u}\right]:$ Solving 
completely for $B$ yields

$$
B=(1-\delta)[c(Q)-c(\underline{q})]-\delta\left[P-c(Q)-\alpha u_{f}^{N_{A}}-(1-\alpha) \bar{u}\right]
$$

We can substitute 17 into the objective function and write the principal's objective function in Langrangian form:

$$
\begin{gathered}
r(Q)-P-(1-\delta)[c(Q)-c(\underline{q})]+\delta\left[P-c(Q)-\alpha u_{f}^{N_{A}}-(1-\alpha) \bar{u}\right] \\
+\lambda\left\{P+(1-\delta)[c(Q)-c(\underline{q})]-\delta\left[P-c(Q)-\alpha u_{f}^{N_{A}}-(1-\alpha) \bar{u}\right]-c(Q)-\alpha u_{f}^{N_{A}}-(1-\alpha) \bar{u}\right\}
\end{gathered}
$$

The associated Kuhn-Tucker conditions are:

$$
\begin{gathered}
r^{\prime}(Q)-c^{\prime}(Q) \leq 0 \\
-1+\delta+\lambda[1-\delta] \leq 0
\end{gathered}
$$

Subsubcase(1bi): $\lambda>0$. This case implies that the participation constraint is binding and therefore $P$ cannot be lowered without bound. By K-T condition 20, $\lambda=1$. Moreover, K-T condition $19 r^{\prime}(Q)=c^{\prime}(Q)$ implies that $\tilde{Q}=Q^{*}$. To solve for $\tilde{P}$ use the participation constraint $P+B(\tilde{Q})-c(\tilde{Q})=\alpha u_{f}^{N_{A}}+(1-\alpha) \bar{u}$. Plug in $B(\tilde{Q})=(1-\delta)[c(\tilde{Q})-c(\underline{q})]-\delta\left[P-c(\tilde{Q})-\alpha u_{f}^{N_{A}}-(1-\delta) \bar{u}\right]$ and then solve for $P$ to get $\tilde{P}=\alpha u_{f}^{N_{A}}+(1-\alpha) \bar{u}+c(\underline{q})$. Now plugging back into $B(\tilde{Q})=(1-\delta)[c(\tilde{Q})-$ $c(\underline{q})]-\delta\left[P-c(\tilde{Q})-\alpha u_{f}^{N_{A}}-(1-\delta) \bar{u}\right]$ yields $B(\tilde{Q})=c(\tilde{Q})-c(\underline{q})$ Therefore, the optimal contract is characterized by:

$$
\begin{aligned}
& r^{\prime}(\tilde{Q})=c^{\prime}(\tilde{Q}) \text { where } \tilde{Q}=Q^{*} \\
& \tilde{P}^{L}=\alpha u_{f}^{N_{A}}+(1-\alpha) \bar{u}+c(\underline{q})
\end{aligned}
$$




$$
B^{L}(\tilde{Q})=c(\tilde{Q})-c(\underline{q})
$$

Subsubcase(1bii): $\lambda=0$. The Kuhn-Tucker conditions are:

$r^{\prime}(Q)-c^{\prime}(Q) \leq 0$

$-1+\delta \leq 0$

The second condition implies that $P$ can be lowered without bound if $\delta<1$. Note that with the bonus fixed at $B(\tilde{Q})=c(\tilde{Q})-c(\underline{q})$, we have $P+B(\tilde{Q})-c(\tilde{Q})=$ $-\infty+c(\tilde{Q})-c(\underline{q})-c(\tilde{Q})<\bar{u}$. Hence, this case cannot induce agent participation and therefore cannot be an optimal solution.

Now that we have analyzed all subcases, note that subsubcases $(1 \mathrm{Ai})$ and $(1 \mathrm{Bi})$ both implement the optimal $\tilde{Q}=Q^{*}$. Using the same steps, we can easily show that any $B(\tilde{Q})=\bar{B}(\tilde{Q})=k B^{H}(\tilde{Q})+(1-k) B^{L}(\tilde{Q})$ for $k \in(0,1)$ is also a self-enforcing bonus that implements $\tilde{Q}=Q^{*}$ and can be made to induce agent participation by choosing some $\tilde{P}=\bar{P}$ such that $\bar{P}+\bar{B}(\tilde{Q})-c(\tilde{Q})=\alpha u_{f}^{N_{A}}+(1-\alpha) \bar{u}$

Case 2: $\hat{Q}<Q^{*}$ : Then $r^{\prime}(\hat{Q})>c^{\prime}(\hat{Q})$ so the principal will contract for $\tilde{Q}=\hat{Q}$ and offer payments $B(\tilde{Q})=\frac{\delta}{1-\delta}\left[r(\tilde{Q})-c(\tilde{Q})-\alpha \pi_{f}^{N_{A}}-(1-\alpha) \bar{\pi}-\alpha u_{f}^{N_{A}}-(1-\alpha) \bar{u}\right]=$ $c(\tilde{Q})-c(\underline{q})$ which just satisfies 9 with equality. To satisfy the participation constraints, the principal must choose $\tilde{P}$ such that $\tilde{P}+B(\tilde{Q})-c(\tilde{Q})=\alpha u_{f}^{N_{A}}+(1-\alpha) \bar{u}$. This is achieved with $\tilde{P}=\frac{\alpha u_{f}^{N_{A}}+(1-\alpha) \bar{u}+c(\tilde{Q})}{1-\delta}-\frac{\delta}{1-\delta}\left\{r(\tilde{Q})-\alpha \pi_{f}^{N_{A}}-(1-\alpha) \bar{\pi}\right\}=\alpha u_{f}^{N_{A}}+(1-\alpha) \bar{u}$.

Thus, both Cases (1) and (2) yield contracts that satisfy the conditions outlined in Proposition 1. 


\section{Proof of Proposition 2}

Proof. If there exists $\tilde{Q}$ such that $S\left(Q^{*}\right) \geq S(\tilde{Q})>S\left(Q_{f}^{N_{A}}\right)$ and $\delta \geq \underline{\delta}(\tilde{Q})$, then $\tilde{Q}$ is a self-enforcing level of quality that yields higher surplus than the best complete contract. Therefore, the principal can always allocate enough surplus to the agent to make the agent at least as well off as he is under the best complete contract, while leaving herself at least as well off as she is under the best complete contract. Thus, $\tilde{Q}$ is a self-enforcing quality level that satisfies all constraints in 2-5 that can be made jointly preferred by the principal and agent.

\section{Proof of Corollary 1}

Proof. Part 1: By Lemma 2, $\lim _{N_{A} \rightarrow \infty} S\left(Q^{*}\right)-S\left(Q_{f}^{N_{A}}\right)=S\left(Q^{*}\right)-S\left(Q_{f}^{N_{A}}\right)=r\left(Q^{*}\right)-$ $c\left(Q^{*}\right)-\bar{u}-\bar{\pi}-r\left(Q_{f}^{N_{A}}\right)+c\left(Q_{f}^{N_{A}}\right)+\bar{u}+\bar{\pi}=r\left(Q^{*}\right)-c\left(Q^{*}\right)-\left[r\left(Q_{f}^{N_{A}}\right)-c\left(Q_{f}^{N_{A}}\right)\right]=0$. Moreover, because $r\left(Q^{*}\right)-c\left(Q^{*}\right)-[r(\tilde{Q})-c(\tilde{Q})]<r\left(Q^{*}\right)-c\left(Q^{*}\right)-\left[r\left(Q_{f}^{N_{A}}\right)-c\left(Q_{f}^{N_{A}}\right)\right]$ for all $\tilde{Q} \in \tilde{\mathbb{Q}}$, it follows that we also have $\lim _{N_{A} \rightarrow \infty} r\left(Q^{*}\right)-c\left(Q^{*}\right)-[r(\tilde{Q})-c(\tilde{Q})]=0$ and $\lim _{N_{A} \rightarrow \infty} r(\tilde{Q})-c(\tilde{Q})-\left[r\left(Q_{f}^{N_{A}}\right)-c\left(Q_{f}^{N_{A}}\right)\right]=0$.

By assumption, $S\left(Q^{*}\right)=r\left(Q^{*}\right)-c\left(Q^{*}\right)-\bar{u}-\bar{\pi}>0$. Thus, there exists some $K$ such that for $N_{A}>K$, we have $\alpha=1$ and 6 becomes $\frac{c(\tilde{Q})-c(q)}{r(\tilde{Q})-c(\underline{q})-\left[r\left(Q_{f}\right)-c\left(Q_{f}\right)\right]}$. The latter term can be rewritten as $\frac{c(\tilde{Q})-c(\underline{q})}{r(\tilde{Q})-c(\tilde{Q})-\left[r\left(Q_{f}\right)-c\left(Q_{f}\right)\right]+c(\tilde{Q})-c(\underline{q})}=\frac{c(\tilde{Q})-c(q)}{[c(\tilde{Q})-c(\underline{q})]\left[\frac{r(\tilde{Q})-c(\tilde{Q})-\left[r\left(Q_{f}\right)-c\left(Q_{f}\right)\right]}{c(\tilde{Q})-c(\underline{q})}+1\right]}=$ $\frac{1}{\left[\frac{r(\tilde{Q})-c(\tilde{Q})-\left[r\left(Q_{f}\right)-c\left(Q_{f}\right)\right]}{c(\tilde{Q})-c(\tilde{q})}+1\right]}$. Since $\lim _{N \rightarrow \infty} r(\tilde{Q})-c(\tilde{Q})-\left[r\left(Q_{f}\right)-c\left(Q_{f}\right)\right]=0$ and the limit of $c(\tilde{Q})-c(\underline{q})$ is some finite positive number, it follows that $\lim _{N \rightarrow \infty} \underline{\delta}(\tilde{Q})=$ $\lim _{N \rightarrow \infty} \frac{1}{\left[\frac{r(\tilde{Q})-c(\tilde{Q})-\left[r\left(Q_{f}\right)-c\left(Q_{f}\right)\right]}{c(\tilde{Q})-c(\underline{q})}+1\right]}=1$

Part 2: 2A: If $\delta \geq \underline{\delta}(\tilde{Q})$ continues to hold after an exogenous decrease in $\delta$, then the principal continues to contract for $\tilde{Q}$ since the Kuhn-Tucker conditions for $Q$ in 
Subsubcases (1Ai) and Subcase (1B) in the proof for Proposition 1 are independent of $\delta$.

2B: If $\delta<\underline{\delta}(\tilde{Q})$, then $\tilde{Q}$ is no longer self-enforcing and cannot be sustained using a relational contract. However, given the assumptions $r^{\prime}(Q)>0, r^{\prime \prime}(Q) \leq 0, c^{\prime}(Q)>0$, and $c^{\prime \prime}(Q)>$ ), one can see from 6 that $\underline{\delta}(Q)$ can be lowered by lowering $Q$. Therefore, for an exogenous decrease in $\delta$, the principal has to lower her preferred quality level from $\tilde{Q}$ to some $\hat{Q}$ such that $\delta=\underline{\delta}(\hat{Q})$. $\hat{Q}$ is self-enforcing and a relational contract that implements $\hat{Q}$ will be preferred to the best complete contract that implements $Q_{f}^{N_{A}}$ if $S(\hat{Q})>S\left(Q_{f}^{N_{A}}\right)$.

$\mathbf{2 C}$ : The proof for this part follows the same steps as the proof for $\mathbf{2 B}$ except if $S(\hat{Q}) \leq S\left(Q_{f}^{N_{A}}\right)$, then the principal prefers the complete contract that implements $Q_{f}^{N_{A}}$ over the relational contract that implements $\hat{Q}$. 